This is the final peer-reviewed accepted manuscript of:

[Hu Xu, Cristina Gentilini, Zhixiang Yu, Xin Qi, Shichun Zhao. An energy allocation based design approach for flexible rockfall protection Barriers. Engineering Structures. Vol. 173, pp. 831-852, 2018]

The final published version is available online at: [https://doi.org/10.1016/j.engstruct.2018.07.018]

Rights / License:

The terms and conditions for the reuse of this version of the manuscript are specified in the publishing policy. For all terms of use and more information see the publisher's website. 


\title{
An energy allocation based design approach for flexible rockfall protection barriers
}

\author{
$\mathrm{Hu} \mathrm{Xu}^{1,2}$, Cristina Gentilini ${ }^{2}$, Zhixiang $\mathrm{Yu}^{1 *}$, Xin $\mathrm{Qi}^{1}$, Shichun Zhao ${ }^{1}$ \\ ${ }^{1}$ School of Civil Engineering, Southwest Jiaotong University, Chengdu, 610031 Sichuan, China \\ ${ }^{2}$ DICAM Department, University of Bologna, Viale del Risorgimento 2, 40136 Bologna, Italy \\ *corresponding author
}

\begin{abstract}
This paper proposes an effective design approach for quickly determining the specification, size and amount of components of a flexible rockfall protection barrier structure. The approach is based on a reliable numerical modelling validated by several experimental tests that include both component tests and full-scale impact tests. The interception structure made up of a steel wire-ring net is accurately investigated through a series of inplane and out-of-plane quasi-static tests carried out on net specimens, to define the ring constitutive model and failure criterion. The accuracy of the numerical strategy for an overall barrier structure with nominal energy level of $1500 \mathrm{~kJ}$ is validated by a full-scale in-situ test including service energy level (SEL) and maximum energy level (MEL) impacts, according to the European guidelines. From the numerical models, it is inferred that the total energy of the impact is simultaneously dissipated in different ways, where the internal energy of the structure plays a significant role. The distribution of the absorbed energy among the different barrier components is explored and defined by means of the developed finite element model. Besides, the design values of the internal force in the ropes are derived with an adequate safety margin. The proposed design procedure, applied to a barrier structure with nominal energy level of $3500 \mathrm{~kJ}$, is assessed by a full-scale impact test, proving that the design approach is reliable and efficient.
\end{abstract}

Keywords: rockfall protection barrier; energy allocation; structural design; wire-ring net; energy dissipating device.

\section{INTRODUCTION}

Protection barrier systems have been evolving since the middle of the last century, starting from an embryonic form of metallic ring nets connecting to float bowls in the water, to intercept submarines and torpedoes in military field during the Second World War. The first application of a barrier to slope disaster prevention dates back to 1951, when the original protection system consisted of wooden columns and steel wire nets for avalanche interception, which subsequently caught many fallen stones by coincidence, so that the rockfall protection barriers were raised and developed [1,2]. 


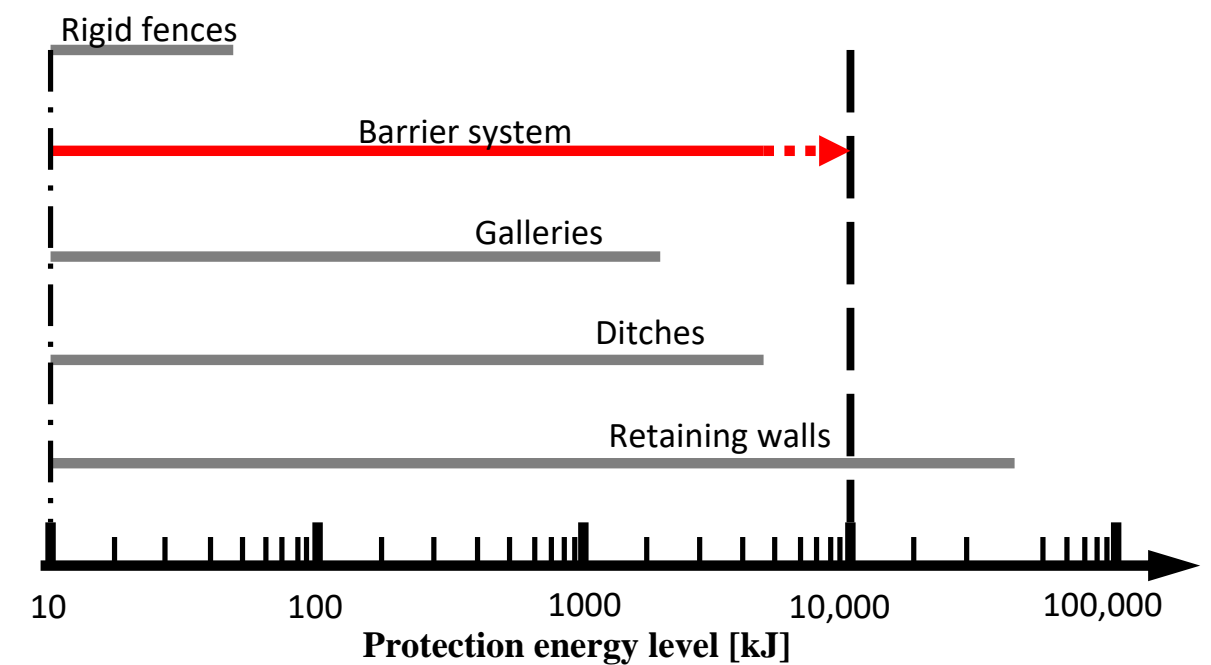

Fig. 1. Protection capacity of common engineering measures against rockfall (modified from [5]).

So far, many different protection measures against geological collapse and rockfall impact can be selected, like rigid fences characterized by an ease installation and ground embankments effective in case of repeated collapse events [3]. Flexible rockfall barriers have become one of the most common measures which cover a wide range of energy absorption capacities ranging from $50 \mathrm{~kJ}$ up to more than $8000 \mathrm{~kJ}$ [4], as shown in Fig. 1 [5]. Flexible barriers are characterized by a high deformability of the interception structure that is typically a steel wire-ring net to which a secondary hexagonal meshwork is fastened on the upslope side, Fig. 2. It is the principal net that bears the block impact, while the secondary meshwork is intended to arrest debris. Wire meshes or a cable nets are also employed as interception structures. Other components of such barriers are the support structure (posts), connecting components (ropes), energy dissipating devices and foundations.

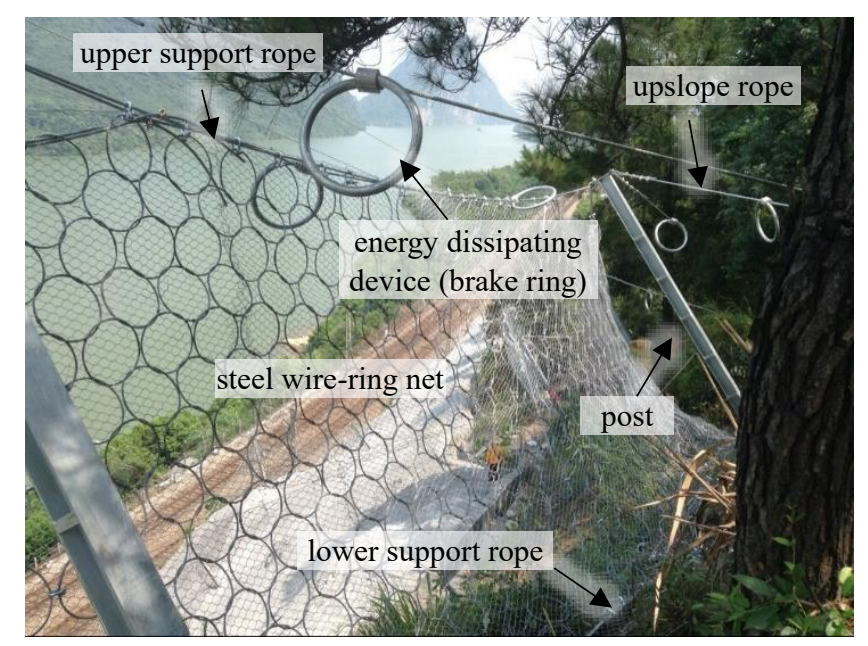

Fig. 2. Typical flexible barrier structure and its main components.

Compared with other engineering structures, there is no specific design standard for flexible rockfall protection barriers. Therefore, in the past several decades, the progress in design theory and the update of the products in this field relied, to a great extent, on the experience of engineers, as well as on the trial-and-error method by means of many experiments [6-13]. However, these tests, carried out by manufacturers and researchers, were developed using different methods and procedures so that the results were not easily 
comparable. For unifying the qualification and improving the performance of the products, the European Organization for Technical Approvals (EOTA) has promulgated a European Technical Approval Guideline (ETAG 027) since 2008, in which a standard full-scale testing procedure was defined [14]. Nowadays, in many countries to ensure a satisfying performance of a rockfall barrier structure, the full-scale impact test based on the standard procedure is compulsory $[15,16]$ or strongly recommended [17]. However, due to the high cost of full-scale tests as for any other complex engineering projects, numerical approaches were used and developed for system analysis and design $[18,19]$.

For the study of rockfall barriers, finite element (FE) [20-27] and discrete element (DE) [28-31] models were both employed, and the validity of these approaches was verified based on available experimental data. In [32], a flexible barrier with nominal energy level of $3000 \mathrm{~kJ}$ was optimized in cost and performance by removing all the energy dissipating devices from the longitudinal ropes and adding just two of them at the outermost portion of the longitudinal upper ropes. In [33], two extreme load cases on a barrier (one was a rock impact with a velocity greater than $25 \mathrm{~m} / \mathrm{s}$ and the other was an impact by a tree trunk with a much smaller puncturing area) were considered for design. A theoretical model in the elasto-plasticity framework for the constitutive behavior of steel wire-ring nets was developed in [34]. In [35], a scaling relationship, validated by means of data generated with a finite element model, was introduced to quantify the capacity of rockfall barriers to withstand impact from blocks, and, in particular, it allowed to investigate the bullet effect. Further, a program capable of analyzing flexible barriers was developed in [36], in which the high nonlinear features of the structure were considered, and an efficient incremental-iterative procedure was adopted for tracing force equilibrium within the barrier system. Besides, maintenance problem of net fences was also dealt using numerical approaches. In particular, the influence of installation issues and deterioration of the system, as well as the damage induced by ageing of the material, were taken into account in [37,38]. Additionally, it should be noted that in the planning phases of rockfall protection devices, a key aspect is the correct definition of the design block and its return period. A probabilistic approach that allows to define this relationship is described in [39] based on statistical analyses of historical data sets (see, among the others, [40]).

Although numerical simulations could significantly enhance the efficiency of design effort, owing to the complexity of the systems, some aspects still need further improvements, such as an accurate definition of the contact among the components and failure criteria. Besides, the wide application of numerical simulations in practical design may also be restricted by the unfeasibility of a too sophisticated modelling.

Most of the available studies involving design methods for barrier structures mainly focused on the initial conditions or input parameters such as the trajectory of the falling rock, the incidence angle and initial velocity, [41-44], rather than on the mechanical properties and dynamic response of the structure. On the contrary, few researches have considered effective and rapid design methods that dealt with the barrier as a whole, which can, to some extent, replace the full-scale dynamic tests and the numerical simulations.

Within this context, a simplified and quick design approach based on energy allocation for flexible barrier structures is herein proposed. To this aim, a reliable numerical model is developed as an analysis tool. A series of tests under quasi-static loadings was conducted to calibrate the dominant parameters of key barrier 
components such as the wire-ring net and the energy dissipating devices. In particular, energy dissipating devices were tested following the recommendations of the ETAG027 [15], where it is suggested the execution of quasi-static tests. However, for an accurate analysis of the brake behavior more close to real loading conditions, the performance of dynamic tests is advisable as highlighted in [7].

Additionally, a full-scale dynamic impact test on a barrier structure of capacity $1500 \mathrm{~kJ}$ was carried out according to the European guideline [15], to verify the accuracy of the numerical model. Accordingly, the relationship among the nominal energy, the total energy of the impact and the design energy was discussed, and the distribution of the dissipated energy of the different barrier parts was studied. Internal forces of each steel wire rope were evaluated, and magnified with safety factors for the design. Based on that, a rapid procedure for determining each component specification is presented and applied to a new barrier structure with nominal energy level of $3500 \mathrm{~kJ}$. Finally, an additional full-scale test on such barrier validated the proposed method, and the comparison between design values and experimental results showed that the approach is reliable.

The paper is organized as follows: the details of the experiments conducted on barrier components and on a full-scale barrier are given in Section 2; the numerical models of the components and of the whole barrier are described in Section 3; the composition of the total energy consumed by the barrier, and its distribution among each part, as well as the prediction of the peak forces in the different ropes, are discussed in Section 4. Finally, the design approach is applied to another full-scale barrier and assessed experimentally in Section 5.

\section{EXPERIMENTAL PROGRAM}

In this section, the experimental tests conducted on barrier components (wire-ring net specimens and energy dissipating devices) and on a full-scale barrier prototype are presented and described. In particular, both inplane and out-of-plane tests were conducted on ring specimens and net panels to accurately explore their mechanical behavior which enables the calibration of a FE numerical model.

\subsection{Component tests: wire-ring net and energy dissipating devices}

A series of component tests was carried out under quasi-static loading conditions in laboratory, including tests on wire-ring net specimens and on energy dissipating devices. 

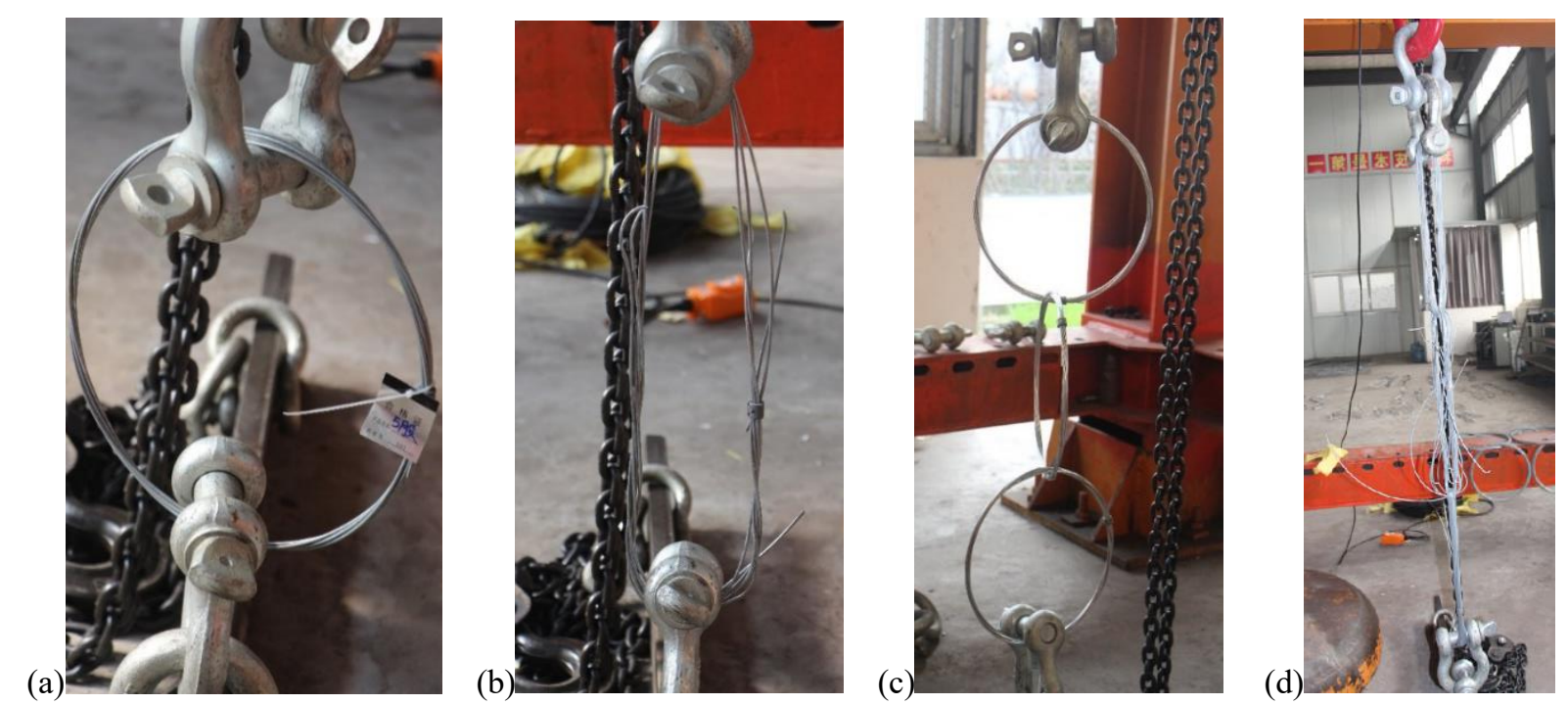

Fig. 3. Tensile tests on ring specimens: (a) one-ring specimen at the beginning of the test; (b) failure of the one-ring specimen; (c) three-ring specimen at the beginning of the test and (d) failure of the three-ring specimen.

Four types of wire-ring specimens were considered: one-ring, three-ring and five-ring specimens as well as net panels. For the first two types, six groups of specimens, depending on the number of windings of the rings (R5, R7, R9, R12, R16, R19) were tested. As shown in Fig. 3, the one- and three-ring specimens were connected with shackles to the testing machine and loaded vertically. The configuration of the loading equipment is shown in Fig. 4, consisting of a steel frame, hydraulic jack, load cell and displacement sensor. The length and width of the frame were both $3.15 \mathrm{~m}$, while the height was $3.3 \mathrm{~m}$. The maximum measurement range of the load cell and displacement sensor were $500 \mathrm{kN}$ and $3 \mathrm{~m}$, respectively.

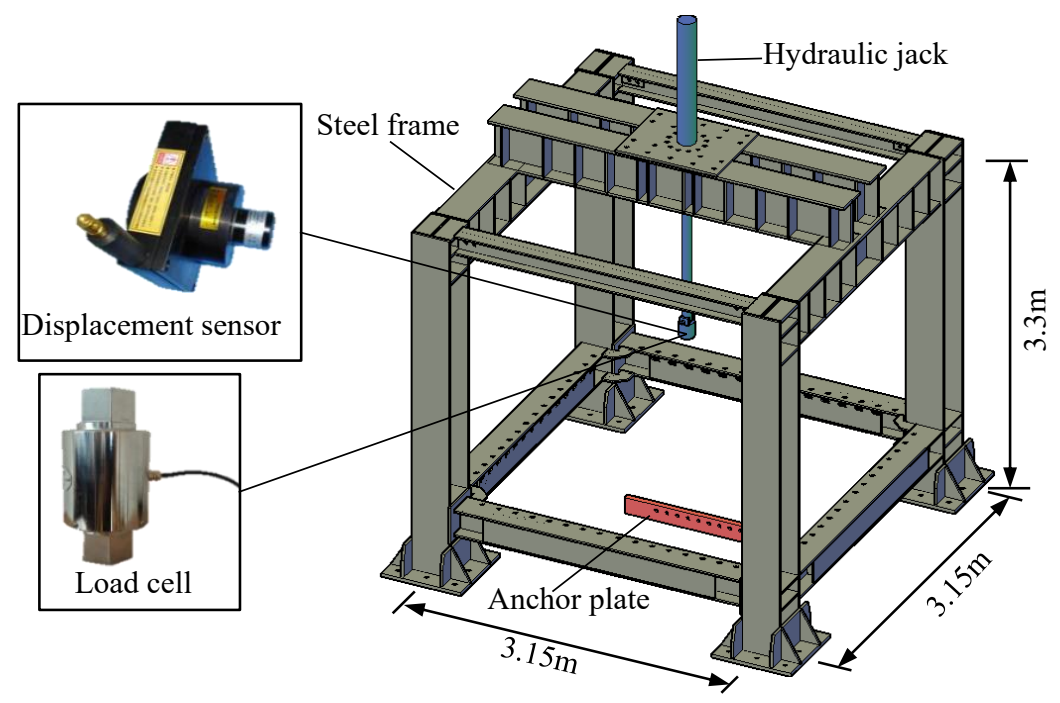

Fig. 4. Steel frame loading equipment system used in the component tests. 
(a)

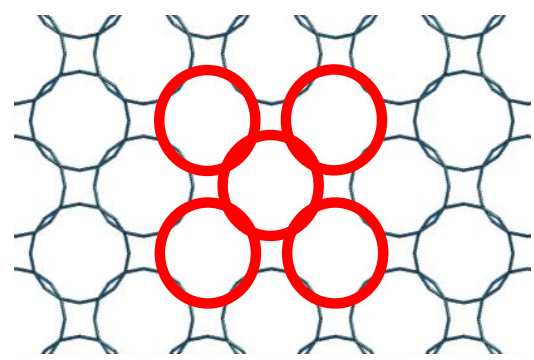

(b)

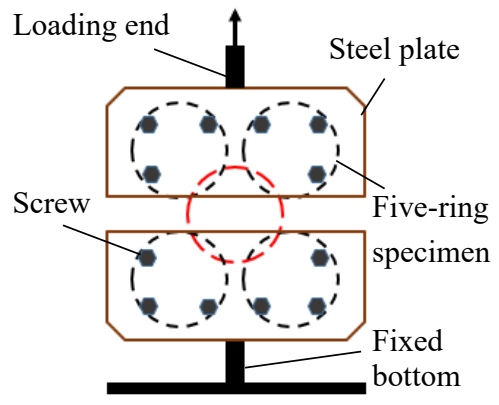

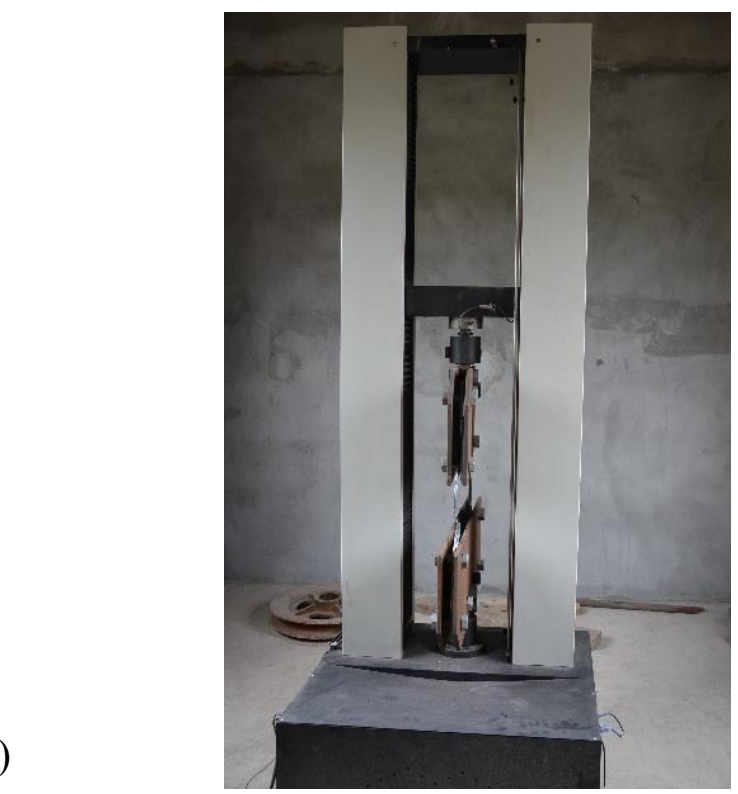

(c)

Since the interception net is composed by wire-rings each of which connects other four rings, five-ring specimens were selected as the typical basic unit of the net panel, Fig. 5a. In the in-plane test, the outer rings were constrained by three screw rods to the steel plates as represented in Fig. 5b. The set-up for the in-plane tensile test of the five-ring specimens is represented in Fig. 5c, where the upper plates were loaded upwards to stretch the specimen.

The out-of-plane puncturing test on a net panel was carried out according to the procedure suggested in [45]. The test consisted in loading a net panel (of quadrangular shape with length and width equal to $3.0 \mathrm{~m}$ ) perpendicularly to its plane by means of a steel hemispherical-shaped loading device, located centrally, Fig. 6a. The influence of the shape of the loading device and of the constraints of the panel to the rigid frame was deeply investigated in $[46,47]$.

In the present test, the net specimen was connected to the steel frame structure with shackles at all the boundary rings, Fig. 6b. A R5 wire-ring net specimen was punctured upwards till failure. The force-displacement curve of the central point of the panel was derived.

(a)
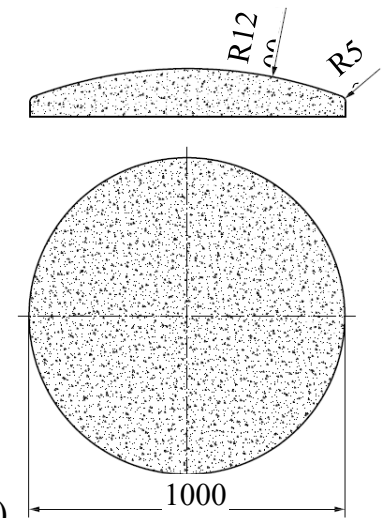

Fig. 6. Out-of-plane puncturing test on the net panel: (a) dimensions of the thrust device in mm and (b) net panel during

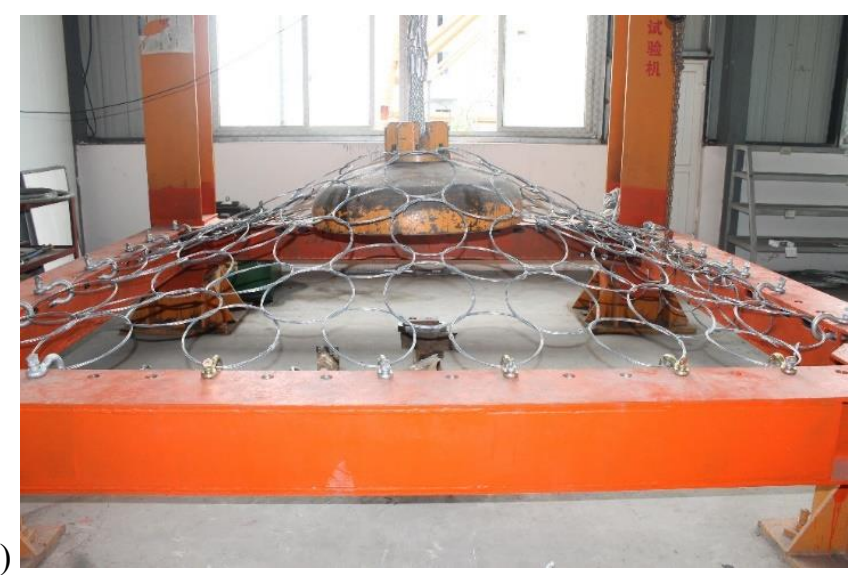

(b) 
the test.

The energy dissipating devices considered in this study are the brake rings, belonging to the friction-plastic deformation mixed mechanism type, represented in Fig. 7a. The brake ring is constituted by an aluminum sleeve (length equal to $80 \mathrm{~mm}$ ) and a steel ring tube (inner diameter, cross-sectional diameter and thickness equal to $402 \mathrm{~mm}, 42 \mathrm{~mm}$ and $6 \mathrm{~mm}$, respectively) with a steel-wire rope passing through it. The brake ring is manufactured as a replaceable unit in the rockfall barriers using the aluminum-alloy swaged ferrule fix the steel wire rope slings, Fig. 7a. In order to derive the essential mechanical parameters, such as activation force, working force and braking displacement [48], three brake rings were stretched up to obtain the forcedisplacement curves, following the ETAG027 [15] recommendations. A photo of a tested brake ring at failure is given in Fig. $7 \mathrm{~b}$.

(a)

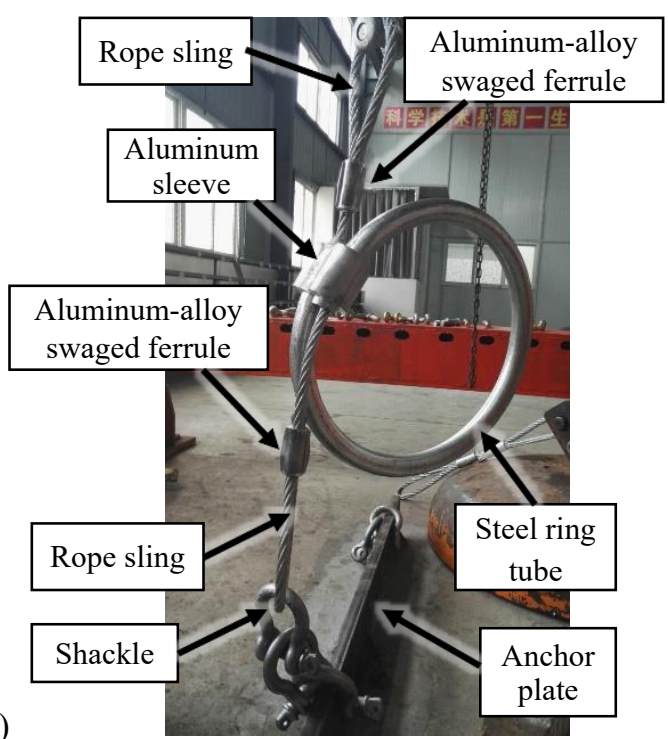

(b)

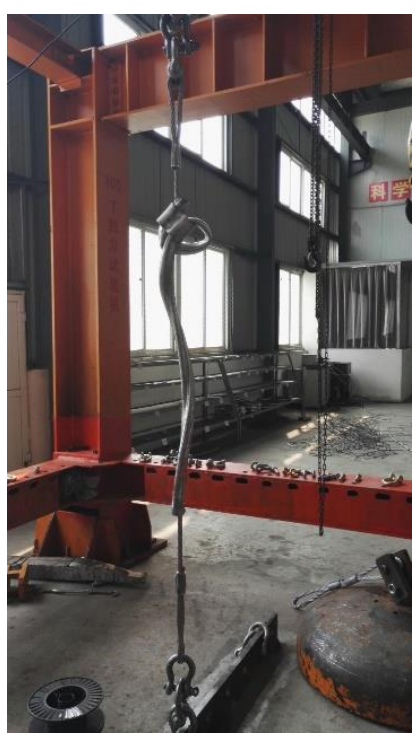

Fig. 7. Test on the energy dissipating devices: (a) main components of the brake ring specimen and (b) failure of the specimen after the tensile test.

All the tests on wire-ring specimens and brake rings were conducted at a constant displacement rate equal to $2 \mathrm{~mm} / \mathrm{s}$ till failure. A summary of the tested barrier components is reported in Table 1 .

Table 1. Component tests on wire-ring net and energy dissipating devices.

\begin{tabular}{|c|c|c|c|c|}
\hline Barrier component & Specimen & Number of windings & Specimen number & Test type \\
\hline \multirow{10}{*}{ Wire-ring net } & \multirow{6}{*}{$\begin{array}{l}\text { One-ring } \\
\text { and } \\
\text { three-ring } \\
\text { specimen }\end{array}$} & $\mathrm{R} 5$ & 3 & \multirow{6}{*}{ In-plane tensile test } \\
\hline & & R7 & 3 & \\
\hline & & R9 & 3 & \\
\hline & & R12 & 3 & \\
\hline & & R16 & 3 & \\
\hline & & R19 & 3 & \\
\hline & \multirow{3}{*}{$\begin{array}{l}\text { Five-ring } \\
\text { specimen }\end{array}$} & R5 & 1 & \multirow{3}{*}{ In-plane tensile test } \\
\hline & & R7 & 1 & \\
\hline & & R9 & 1 & \\
\hline & Net panel & R5 & 1 & Out-of-plane puncturing test \\
\hline $\begin{array}{c}\text { Energy dissipating } \\
\text { devices }\end{array}$ & Brake ring & / & 3 & In-plane tensile test \\
\hline
\end{tabular}

\subsection{Full-scale impact tests}


The test site located in Guanghan city (Sichuan, China) belongs to the artificial type class, in which a threefunctional module barrier prototype is subjected to a vertical impact at the center of the middle module. As shown in Fig. 8, the test site consists of a RC reaction wall and a travelling portal crane. The reaction wall (length, height, and thickness equal to $38 \mathrm{~m}, 13.5 \mathrm{~m}$, and up to $1.5 \mathrm{~m}$, respectively) is perforated at intervals of $0.5 \mathrm{~m}$ to insert the anchorage bolts of the steel wire ropes and posts. A crane is able to raise the impactor to a maximum height up to $40 \mathrm{~m}$ from the barrier plane, which can generate a free falling velocity of $28 \mathrm{~m} / \mathrm{s}$ to impact the barrier structure. The impactors are concrete polyhedral blocks confined by steel plates, providing a series of masses with different dimensions. A high speed camera, with a frequency of $1000 \mathrm{fps}$, is employed to record the impact.

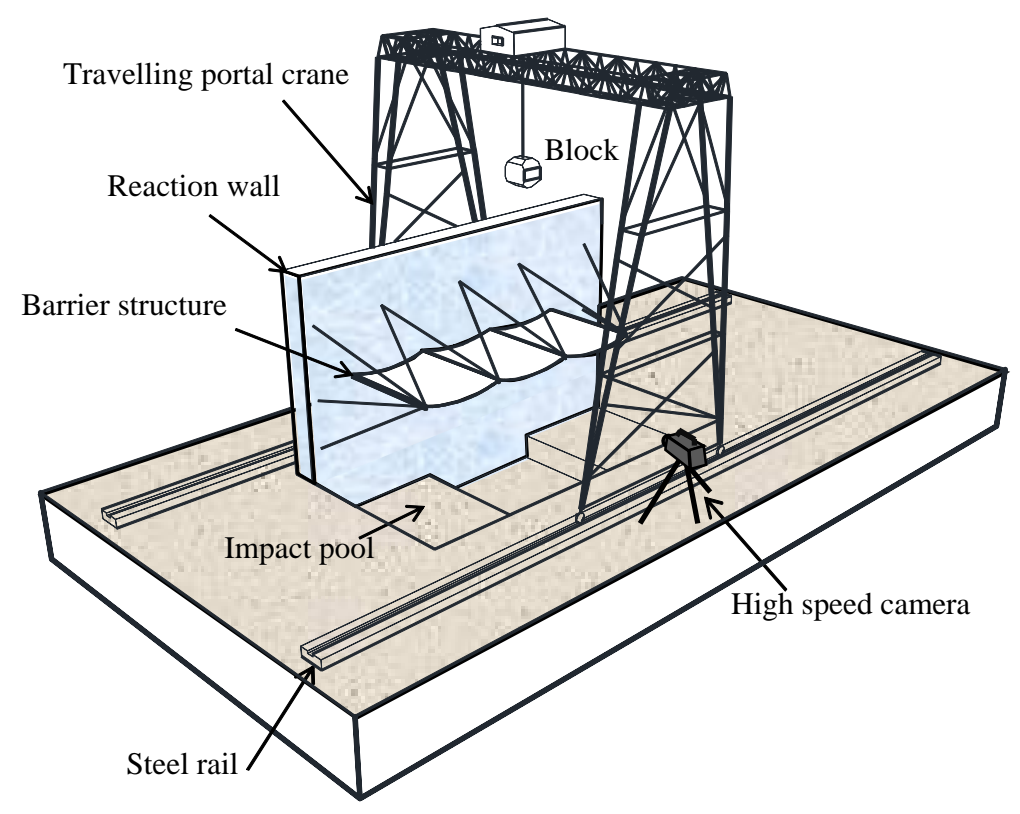

Fig. 8. Schematic view of the artificial test site in Guanghan city (Sichuan, China).

A full-scale barrier structure with nominal energy absorption capacity of $1500 \mathrm{~kJ}$, hereinafter named barrier 1500, was tested in the Guanghan test site. Following the European guidelines [15], the barrier prototype has to be impacted three times: the first two impacts at $1 / 3$ of the nominal energy level for the SEL capacity and a last impact at full nominal energy for the MEL capacity.

For the first launch at SEL, a block with a mass of $1562 \mathrm{~kg}$ was lifted up to $32.7 \mathrm{~m}$ to produce a kinetic energy equal to $500 \mathrm{~kJ}$. Then, for the second launch at SEL, after removing the block, the deformed model was impacted at the same spot with the same kinetic parameters of the first test. Before conducting the test at MEL, the barrier was repaired by replacing the wire-ring net and the activated energy dissipating devices. A kinetic energy equal to $1500 \mathrm{~kJ}$ was produced by releasing a $4002 \mathrm{~kg}$ block from a height of $38.2 \mathrm{~m}$.

A sketch of barrier 1500 is given in Fig. 9a. In the picture, the main dimensions of the barrier as well as the position of the sensors (load cells and strain gauges) and energy dissipating devices are reported. Seven types of ropes, named differently by their locations, are set in the structure, including the upper major support rope, the upper minor support rope, the lower major support rope, the lower minor support rope, the edge support ropes, the upslope ropes, and the side anchor ropes. Among the others, both upper and lower major ropes are 
supported by the post ends, and both upper and lower minor ropes, bypassing the post ends, are connected with the net via shackles, Fig. 9b. The detail of the connection of the post head with the support ropes is illustrated in Fig. 9c. Load cells connected with the wire ropes were installed between the anchorages and the energy dissipating devices to measure the internal forces, as shown in Fig. 9d. Strain gauges were applied on the both sides of the web plate of the posts to record the stress state during the impact, as shown in Fig. 9e.

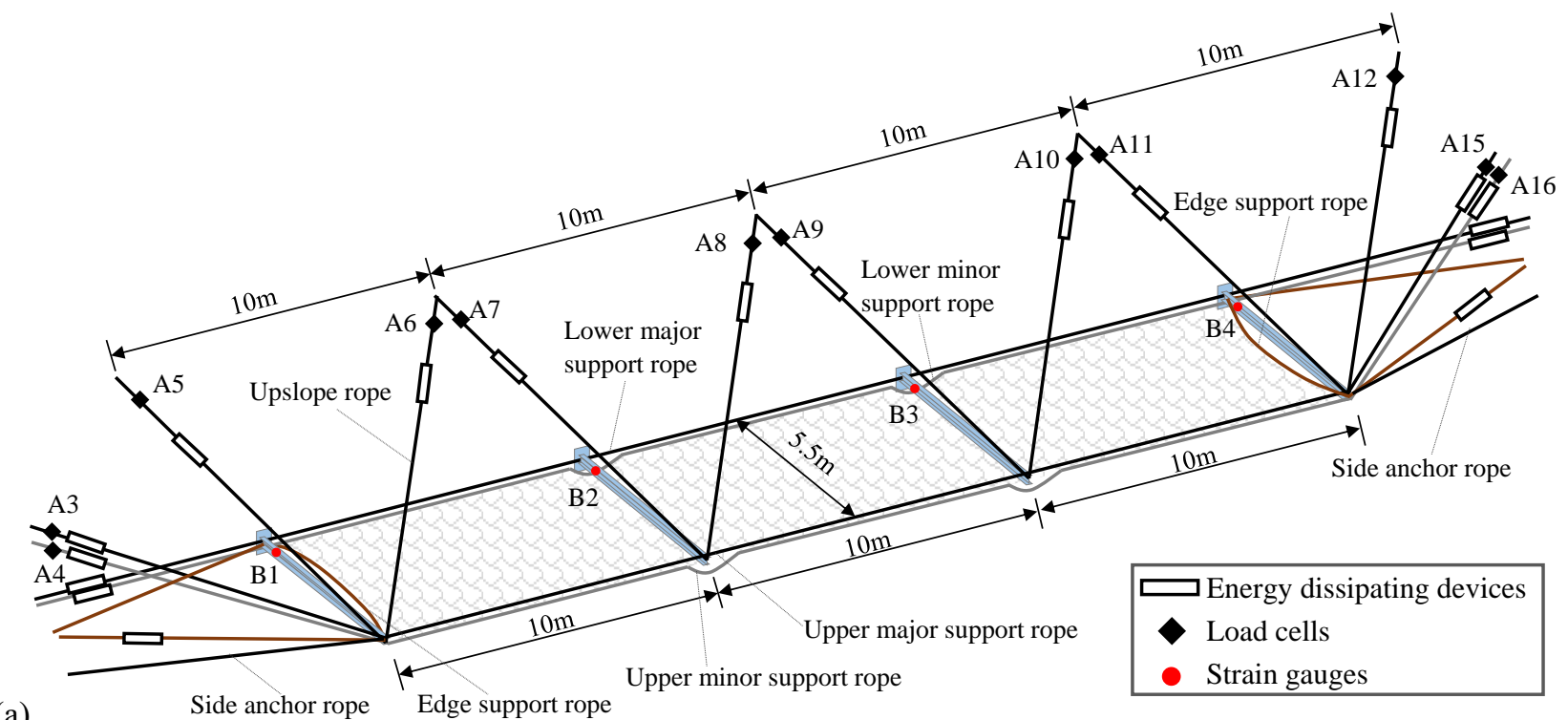

(a)

(b)
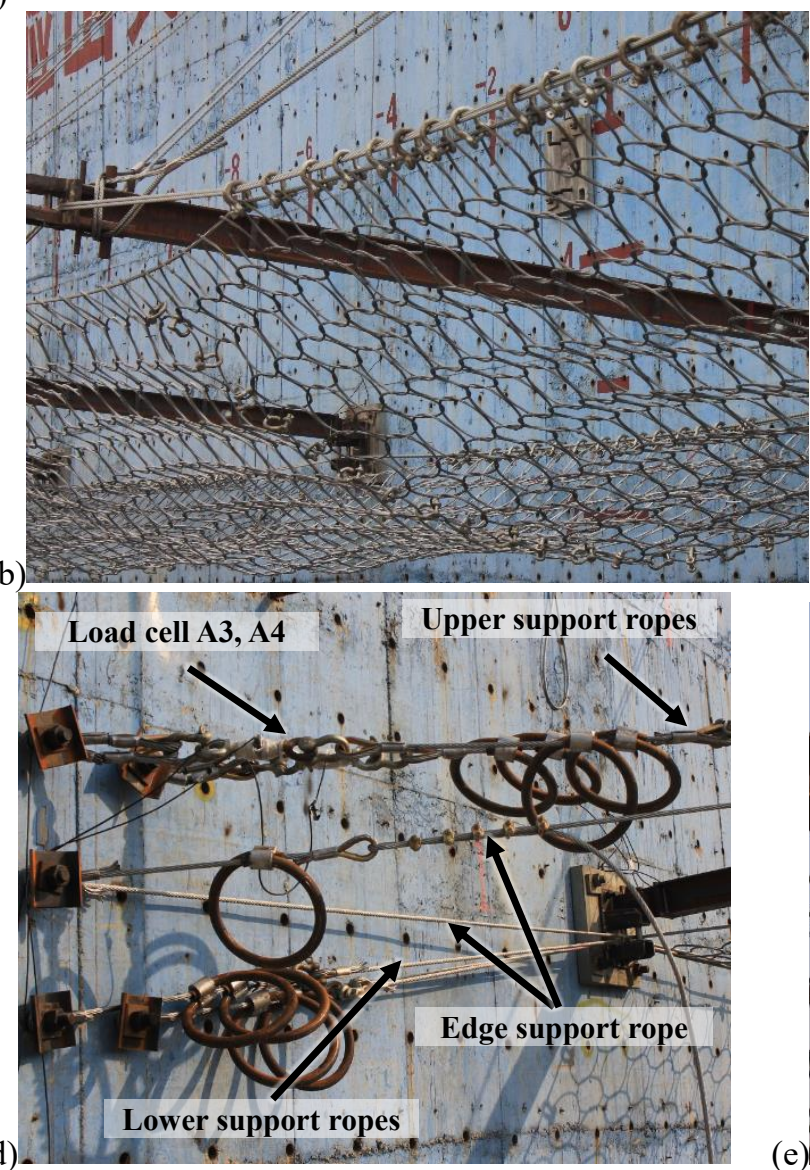
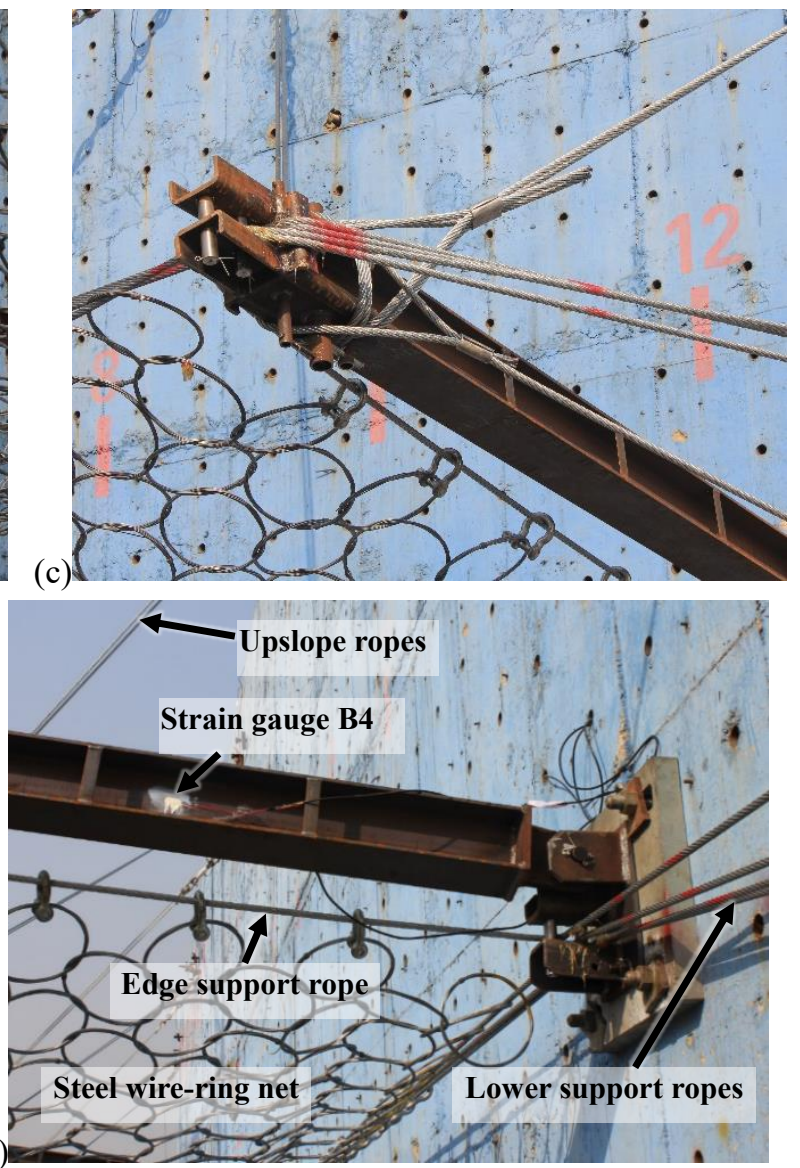

Fig. 9. Barrier 1500: (a) general schematic drawing of the barrier with labeling of sensors and ropes; (b) connection between the wire-ring net and the support ropes; (c) connection between the post head and the support ropes; (d) load cells A3 and A4 installed on the upper support rope and (e) strain gauge B4 installed on the outer post. 


\section{NUMERICAL MODEL: DEVELOPMENT AND CALIBRATION}

Starting from the experimental results on both components and on the full-scale barrier, in this section a numerical model for the tested barrier is developed. Particular emphasis is given to an accurate modelling of the wire-ring net and energy dissipating devices, due to their crucial role in absorbing energy during the impact. For the sake of brevity, only the most representative results of the conducted tests are reported in the following. All the simulations were conducted employing the commercial software program LS-Dyna [49].

\subsection{Modelling of the wire-ring net}

In literature, in order to simplify the numerical analyses, the ring net was modeled with truss elements [20] or with shell elements $[44,50]$. However, the available numerical models fail in simulating the behavior of the rings at large deformation stage due to a lack of experimental validation. In [51], an accurate model that employed beam elements to simulate each individual ring based on general contact algorithm was proposed. In the study, the equivalent cross-sectional area of the beam elements was obtained as the real net section multiplied by a variable reduction factor $\chi(\chi=0.6 \sim 0.8)$, and the plastic strain at failure was defined with a nonlinear function. This method initiated an approach of modelling the wire-ring nets accurately and the factor $\chi$ solved to some extent the problem that wire-rings become over-stiff as the number of windings increases. However, the approach reduced the total mass of the net, which plays a significant role in the dynamic response. In this paper, the wire-ring net is modelled by beam elements with four integration points at the central crosssection. In order to guarantee a correct stiffness and mass of the net, an equivalent cross-section $A_{e q}$ is employed, as given by:

$$
A_{\text {eq }}=n_{\mathrm{w}} A_{0}, \quad d_{\mathrm{eq}}=\sqrt{n_{\mathrm{w}}} d_{0}
$$

where $A_{0}, d_{\mathrm{eq}}, d_{0}$ and $n_{\mathrm{w}}$ are the actual cross-sectional area of a single wire, the equivalent diameter of the beam element, the actual diameter of a single wire and the number of windings, respectively.

(a)

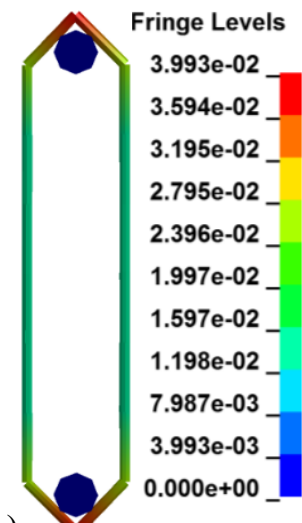

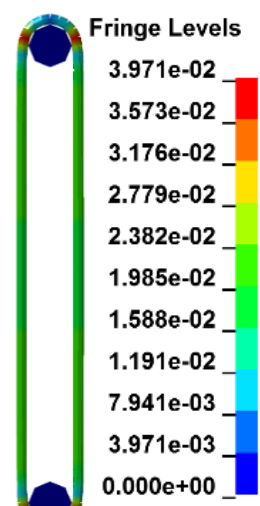

(b)

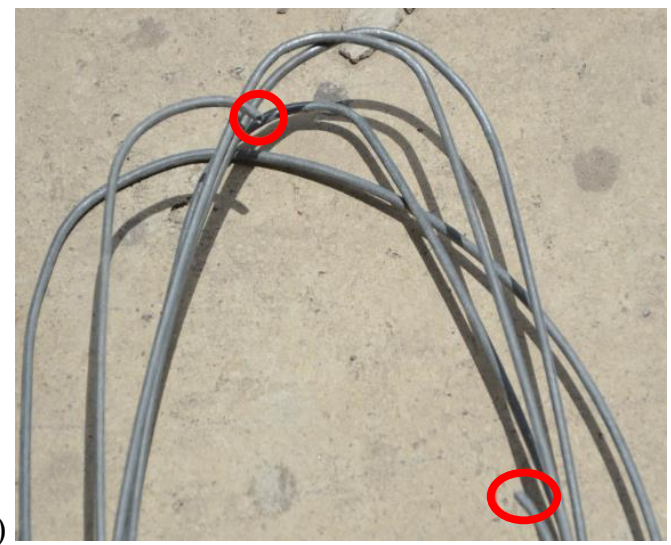

(c)

at failure for one-ring specimen: (a) 16-element mesh;
fracture position observed in the tensile test (R5 ring).

Figure 10 shows the influence of the number of elements on the failure position of one-ring. As expected, a finer mesh (128 elements) leads to a fracture mode much closer to the experimental results. However, a fine mesh leads to a high computational burden, considering the great quantity of elements necessary to model a whole barrier structure. In Fig. 11a, the load-displacement curve obtained experimentally on the R9 one-ring 
specimen, and those derived numerically varying the number of elements are reported as well. The computation is terminated as the reaction force reaches the maximum experimental force. The coarse mesh (16 elements) is definitely stiffer, underestimating the displacement at failure with respect to the test result. It can be seen that results for the 64- and 128-element mesh are much closer to the experimental curve. However, considering the dissipated energy in the different one-ring specimens, Fig. 11b, although the dense mesh (128 elements) brings to a larger displacement close to the actual value, the dissipated energy, which influences the energy allocation of the whole barrier, is not so accurate if compared to that obtained from the experimental tests. In particular, the red columns represent the dissipated energy calculated as the average of the one-ring specimens tested in each group, while the simulation results of both coarse (16 elements) and dense (128 elements) meshes are represented by the dashed and checked columns, respectively. It can be noted, for example considering the R9 results, that the dissipated energy between the two meshes is similar and smaller with respect to the experimental result. In the case of the R19 one-ring specimens, the results obtained from both meshes strongly underestimate the actual dissipated energy (the difference is around $44.1 \%$ ).

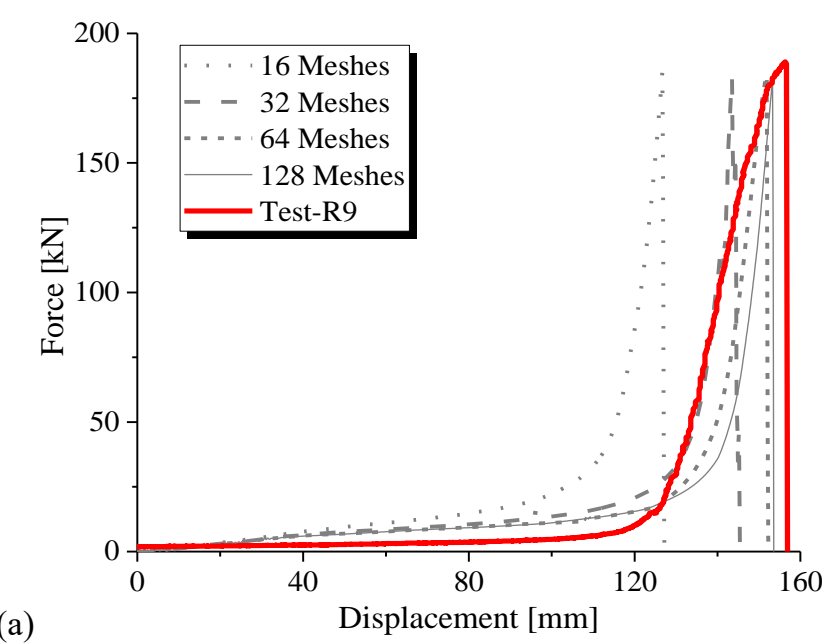

(b)

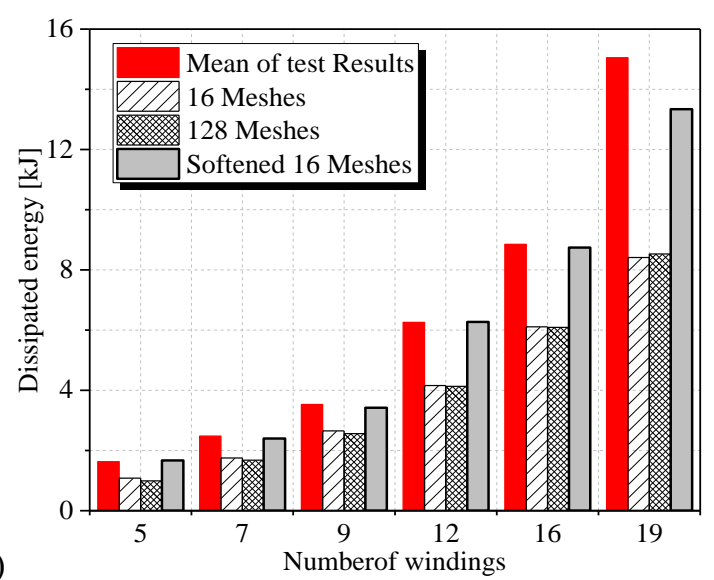

Fig. 11. One-ring specimens: (a) effect of mesh density on load-displacement curves for the R9 ring and (b) dissipated energy for different rings.

In order to represent accurately the load-displacement curve and to dissipate the correct amount of energy during the loading process, an equivalent Young's modulus instead of the original one for the steel wire is introduced herein.

Figure 12a plots the multi-linear constitutive curve adopted in the numerical model for the steel of the rings. The dotted line represents the original stress-strain relationship, in which the data of key points including A $(5.68 \%, 1421.8 \mathrm{MPa}), \mathrm{B}(5.99 \%, 1650.8 \mathrm{MPa}), \mathrm{C}(10.0 \%, 1896.1 \mathrm{MPa})$ and D (14.52\%, 1980.0 MPa) were obtained from the manufacturer. To reflect the loosen state among each winding of the steel wires, the original elastic modulus is softened by means of a trial and error approach, and the plastic part is translated correspondingly. In such a way, it is shown that is possible to obtain accurate results even with few elements (16 for each ring). In Fig. 12b, the simulation results using a 16-element mesh with the softened elastic modulus, are compared with the experimental results for three groups of rings (R5, R9 and R16). A good agreement in stiffness and peak force is revealed, as well as the dissipated energy is much closer to the 
experimental values as shown in Fig. 11b (grey columns). Therefore, in the following, the 16-element mesh with softened stiffness is employed for the simulations of the rings.

(a)

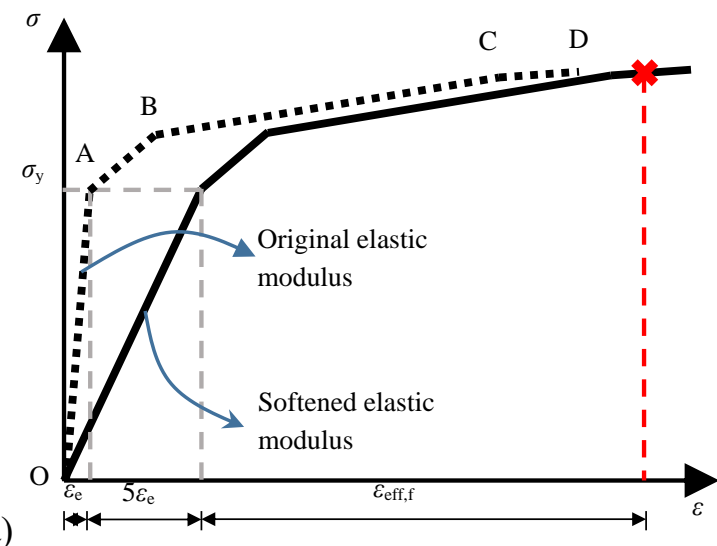

Fig. 12. One-ring specimen tests and simulation: (a) multi-linear constitutive model and (b) load-displacement curves for different rings.

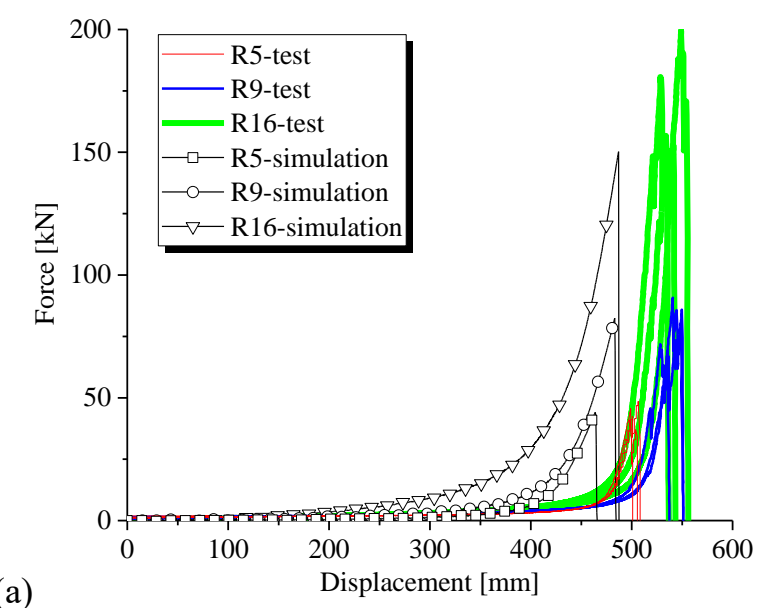

(b)

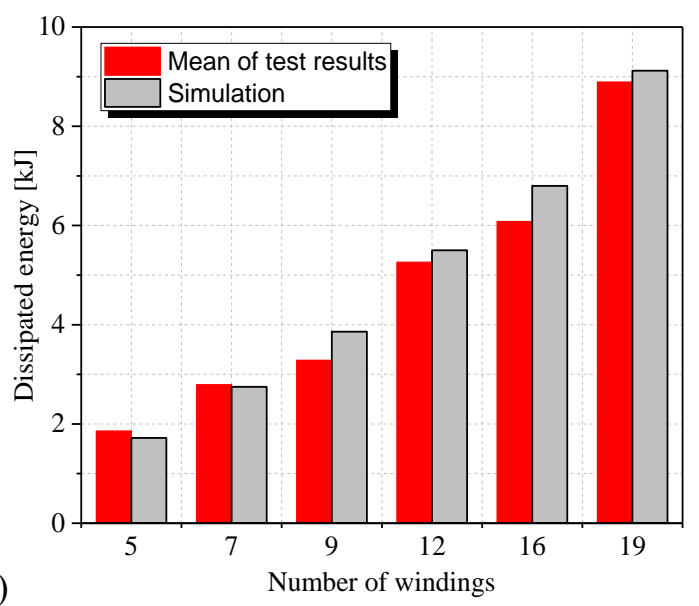

Fig. 13. Three-ring specimen tests and simulation: (a) load-displacement curves and (b) dissipated energy for different rings.

This model was also employed for the three-ring tests. In Fig. 13a, a comparison of the results between simulation and lab tests including R5, R9, and R16 specimens is shown. The maximum deviation of the peak load and displacement at peak between numerical and experimental results is equal to $5.1 \%$ (R9 ring tests) and $11.1 \%$ (R19 ring tests), respectively. Both the numerical and experimental peak forces and ductility are in agreement, as well as the total energy consumption values, Fig. 13b.

Moreover, for predicting the ultimate capacity of the ring net, the effective plastic strain is used as failure index, and the critical values of such parameter are identified by a back-analysis based on the experimental results. According to the above simulations on the one-ring and three-ring specimens, it is indicated that the failure strain increases as the number of windings of the ring increases. However, the breaking force of the wire-ring depends on both the cross-sectional area and the bending diameter [52]. In general, the ultimate strength decreases with a smaller bending diameter, and the plastic strains grow faster, hence the failure strain of one-ring depends on the bending diameter. It is required in ETAG 027 [15] that the diameter of the circular elements for connecting the chain to the machine should be not less than 4 times the diameter of the cross- 
section of the ring. Tensile tests on one- and three-ring specimens with a bending diameter no less than $50 \mathrm{~mm}$ were performed in [53]. In the present study, the bending diameter $d_{B}$ in the ring to ring connection in the three-ring tests is much smaller with respect to the one in the one-ring test, as depicted in Fig. 14a. In fact, in the three-ring tests, the maximum tensile force resulted smaller (53.3\% on average) than the one registered in the one-ring test. Further, all the failures took place at the contact regions of the middle ring with the outer rings, as it can be observed in Fig. 14b.

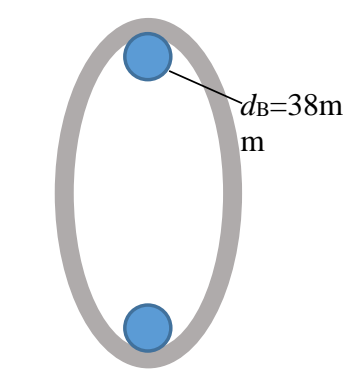

Ring to shackle connection or ring to steel wire rope (a) connection in the actual system

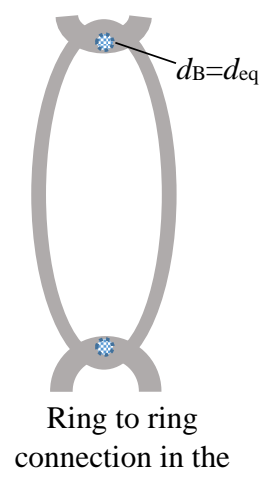

actual system

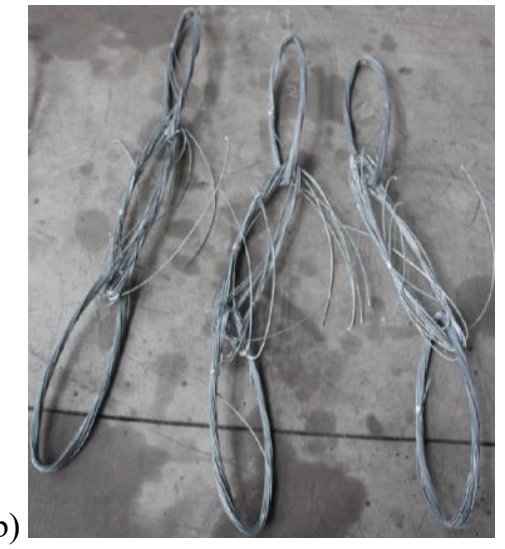

(b)

s: (a) $d_{\mathrm{B}}$ for one-ring and three-ring specimen and (b) failure position of three-ring specimens (R19).

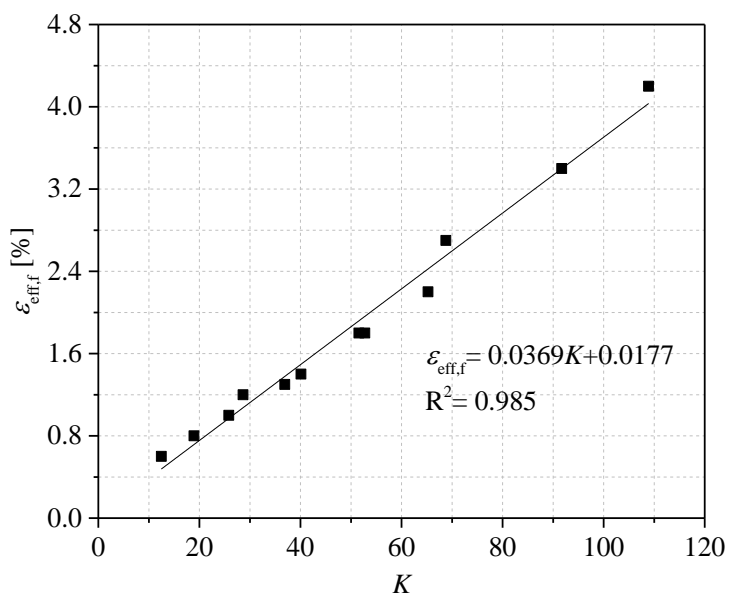

Fig. 15. Effective plastic strain at failure for ring specimens.

Since the ultimate state is affected by the winding number $n_{\mathrm{w}}$ and bending diameter $d_{\mathrm{B}}$, that always vary in different barriers at different energy levels, herein, a factor $K$ is introduced as:

$$
K=d_{B}^{0.48} n_{w}
$$

In Fig. 15, the effective plastic strain at failure $\varepsilon_{\text {eff,f, }}$ obtained from the simulations, is plotted versus factor $K$. Considering a particular wire-ring net with given $n_{\mathrm{w}}$ and $d_{\mathrm{B}}$, factor $K$ can be calculated from Eq. (2), and the corresponding $\varepsilon_{\text {eff,f }}$ is obtained from the linear relationship shown in Fig. 15.

As mentioned in Section 2.1, in-plane tests were carried also on five-ring specimens. Simulations were performed for the five-ring specimens following the approach previously described. A comparison between test and numerical failure mode is given in Fig. 16a. The experimental and numerical force-displacement curves for the five-ring specimens are reported in Fig. 16b. All the calculated peak forces are slightly bigger 
than the test results, and deviations are $9.4 \%, 1.5 \%, 8.5 \%$ for $\mathrm{R} 5, \mathrm{R} 7$, and $\mathrm{R} 9$ test, respectively. The deviations of displacements at peak between the test and simulation are $0.4 \%, 3.6 \%$, and $10.6 \%$, respectively. These differences can be ascribed to many factors, including a measurement inaccuracy in the initial part of the lab tests when the rings passed from the loosen to the tight state. However, the dissipated energy that is an important parameter for the behavior of the net, matches well with a maximum error of $7.8 \%$. Additionally, it is worth noting that the numerical model was calibrated to reach a compromise among several requirements: i) capability of the model to capture peak forces and displacements at peak; ii) capability of the model to capture the initial slope/general trend of the curves; iii) capability of the model to capture the dissipated energy during the test; iv) capability of the model to reproduce the failure mode, and $v$ ) having a low computational cost. All this considered, slight deviations between tests and simulations were considered acceptable and the proposed numerical model was considered suitable for representing the in-plane tensile behavior of the wirering net.

(a)
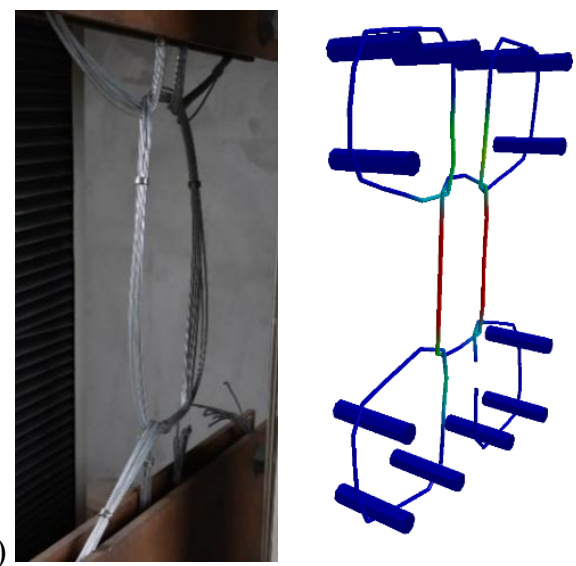

Fig. 16. Five-ring specimen tests and simulation: (a) failure mode (R9) and (b) load-displacement curves for different specimens (the dissipated energy is indicated within parentheses).

For the out-of-plane test, Fig. 17a illustrates the R5 net panel during the test compared with the numerical simulation. According to Eq. (2), considering the bending diameter $d_{\mathrm{B}}$ equal to $d_{\mathrm{eq}}$, factor $K$ can be calculated, and from the formula in Fig. 15, the corresponding effective plastic strain at failure is obtained. The simulation failure mode is characterized by rupture of the wire-ring located neither at the top of the net nor along the border, essentially in agreement with the experimental result shown in Fig. 17b. From the load-displacement curves, Fig. 17c, it can be noted that the experimental ultimate elongation is $709 \mathrm{~mm}$, while numerically a value of $726 \mathrm{~mm}$ is obtained. It should be noted that the starting point of the elongation was considered when the thrust device overcame the weight of the entire net. Both peak loads and displacements at peak show little disparities between test and simulation, being $306 \mathrm{kN}$ and $349 \mathrm{kN}, 1309 \mathrm{~mm}$ and $1370 \mathrm{~mm}$, respectively. These differences may be, to some extent, caused by the restart operation during the test due to the stroke limitation of the loading system. Nevertheless, considering the dissipated energy, test and simulation results are very close with an error of $2.9 \%$, so it can be concluded that the proposed constitutive model is also effective in representing the out-of-plane mechanical behavior of the wire-ring net. 
(a)
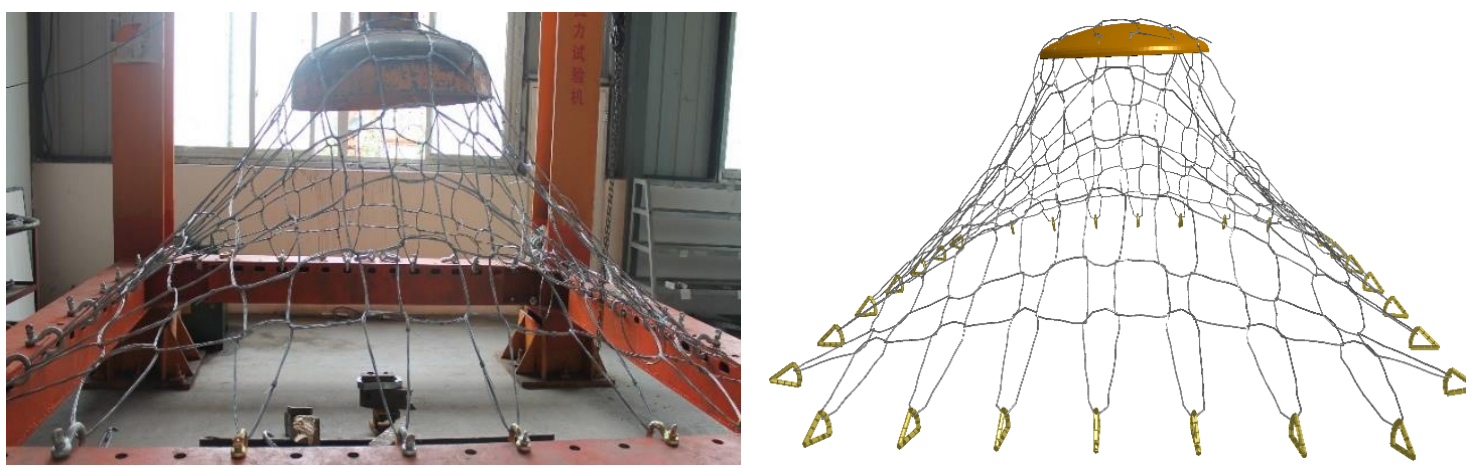

(b)
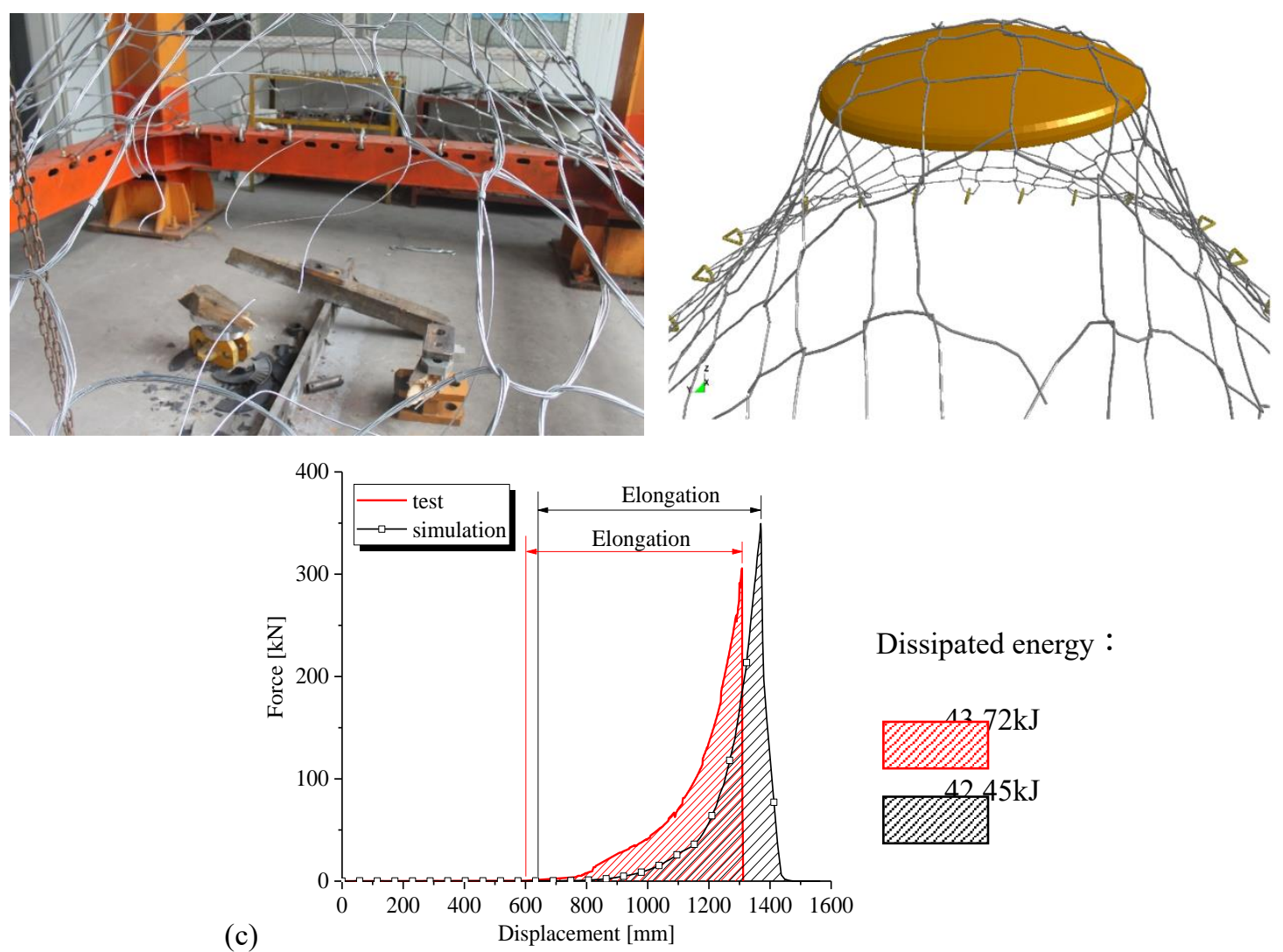

Dissipated energy :

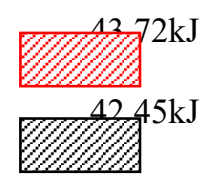

Fig. 17. Net panel tests and simulation: (a) elongation of the net; (b) failure mode and (c) load-displacement curves.

\subsection{Modelling of the energy dissipating devices}

Energy dissipating devices play a key role in absorbing the total kinetic energy from the rockfall $[54,55]$. According to quasi-static and dynamic tests, the mechanical performance of most of these devices under tensile actions was described in detail in literature [56], and all the force-displacement behaviors were simplified as tri-linear or quasi-linear curves to define the numerical model. Based on previous studies on dynamic and static tests conducted on the same type of brake rings employed in the barriers under investigation [48], it was concluded that the key parameters such as activation force, dissipated energy and elongation attained similar values. Additionally, in [32] non-linear dynamic and static analyses were performed on brake elements belonging to the same class of the ones herein considered. Numerical results showed that a tri-linear curve, appropriately calibrated, was suitable to model the behavior of brake. For these reasons, in the present paper, results from the quasi-static tests presented in Section 2.1 were employed to calibrate the load-displacement curve for the energy dissipating device. 


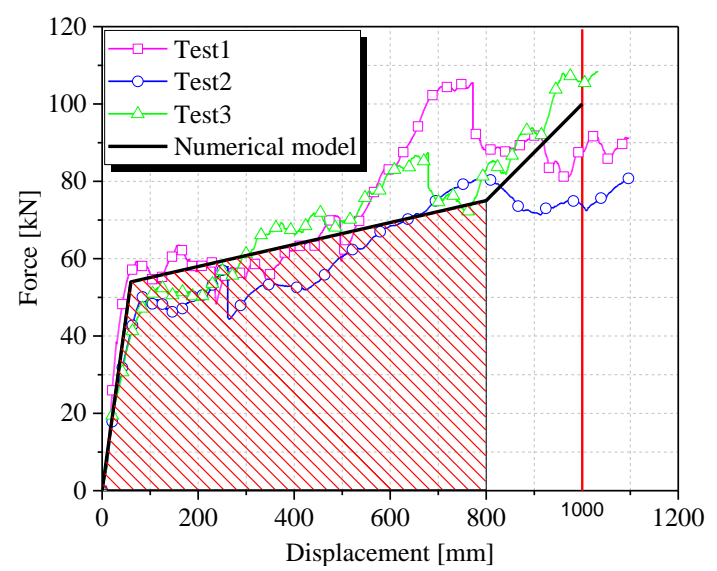

Fig. 18. Energy dissipating devices: test results and numerical model.

The results of the brake ring tests, as described in Section 2.1, are plotted in Fig. 18. From the figure, the average activation force can be identified as $54.1 \mathrm{kN}$. According to the test results, a discrete element with piecewise constitutive law is employed to model the brake devices, black line in Fig. 18. The activation force is set at $54 \mathrm{kN}$ at a displacement of $60 \mathrm{~mm}$, then a yield branch follows, until the force increases up to $75 \mathrm{kN}$ (at $800 \mathrm{~mm}$ displacement). Besides, when the full stroke of the brake ring is almost reached (800 $\mathrm{mm}$ ), the force rises sharply within a very short distance and a steep hardening branch follows. Considering the instability of the hardening branch in the force-displacement curve [56], the design capacity should only take the yielding branch into account. In Fig. 18, the envelope area of the red shadow is equal to $50 \mathrm{~kJ}$, that is defined as the minimum design value of dissipated energy for a single dissipator.

\subsection{Modelling of other components: ropes, posts, constraints and connections}

To represent the nonlinear behavior of the steel wire ropes, 3D cable-discrete elements [49] are employed. The posts in the barrier structure are modelled using user-defined integration beam elements with I-shape crosssection. It should be noted that the high strength steel wire ropes employed in the tested barrier are not characterized by an evident plastic behavior, since brake elements mounted in the ropes limit the attainment of high load levels. For this reason, an elastic-perfectly plastic material law is adopted in the model for ropes and posts, whose constitutive parameters are collected in Table 2.

The foundations of all steel wire ropes are set at the both end nodes, where six degrees-of-freedom (DOFs) are fixed, except for upslope ropes that are constrained at only one end, while the other end is connected to the top of the post with a coincident node. Since the post is able to rotate freely in the vertical plane and rotate finitely in the horizontal plane [51], the bottom node is completely fixed except releasing the rotational DOF around the horizontal axis ( $Y$ axis), while a constrained spring element is set to simulate the actual horizontal rotation (around $Z$ axis) limited by the base plates within a small region, as depicted in Fig. 19a. The moment-rotation curve adopted for the spring is shown in Fig. 19b: the post can swing freely within $\theta_{1}$, for greater rotations a high stiffness limits the movement. The value of $\theta_{1}$ is dominated by the length of the post and the distance between the base plates. In this study, a value of $15^{\circ}$ for $\theta_{1}$ is adopted.

Table 2. Material properties adopted in the numerical models for steel wire ropes and posts. 


\begin{tabular}{ccccc}
\hline Component & Mass density & Poisson's ratio & Elastic modulus & Yield stress \\
\hline Steel wire rope & $7900 \mathrm{~kg} / \mathrm{m}^{3}$ & 0.3 & $1.5 \mathrm{e} 5 \mathrm{MPa}$ & $1770 \mathrm{MPa}$ \\
Steel post & $7900 \mathrm{~kg} / \mathrm{m}^{3}$ & 0.3 & $2.0 \mathrm{e} 5 \mathrm{MPa}$ & $235 \mathrm{MPa}$ \\
\hline
\end{tabular}

(a)

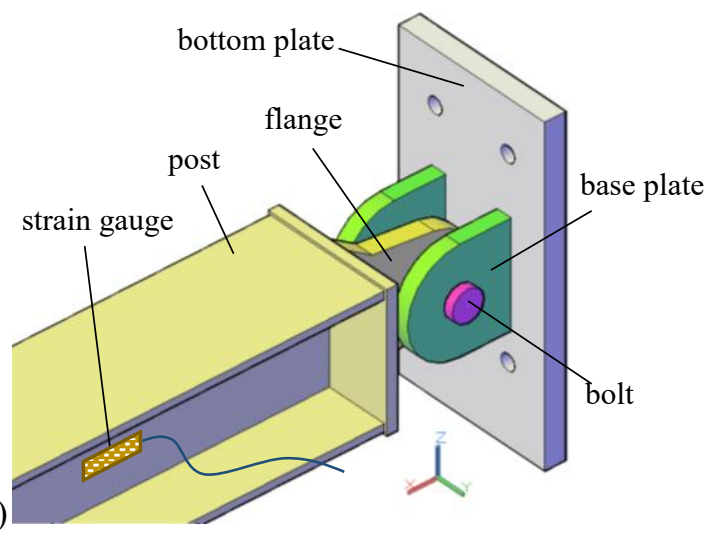

(b)

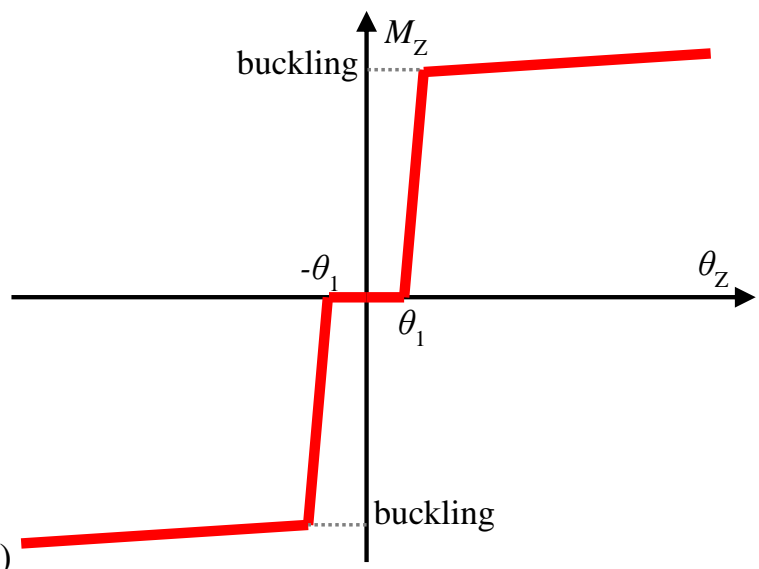

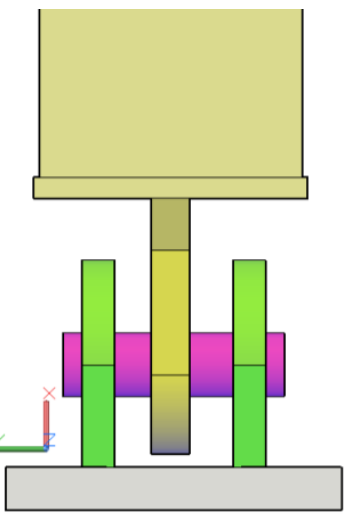

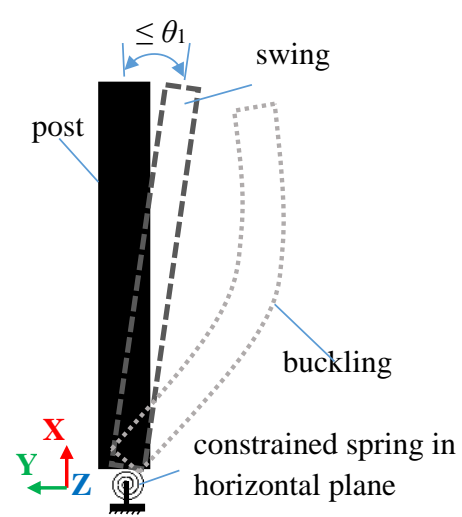

(c)

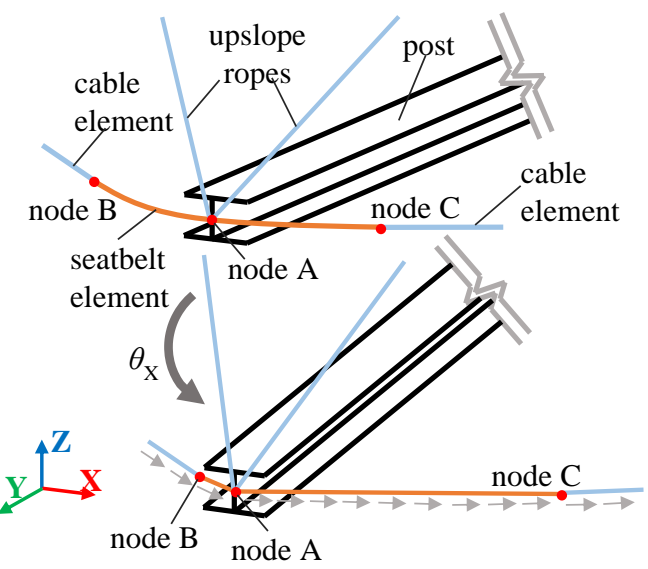

Fig. 19. Boundary conditions and connections: (a) constraint at the bottom end of the posts; (b) moment vs. rotational angle curve adopted for the constrained spring in the horizontal plane (X-Y plane) and (c) slipping of support ropes through the end node of the posts.

During the impact, the wire-ring net slips along the support ropes by means of shackles, that were modeled as rigid bodies in the simulations [49]. A general contact algorithm with Coulomb friction model was employed to enable the wire rings and ropes be connected by the shackles. The upper support and lower support ropes slip through the top and bottom of the post, respectively. The slipping feature between the ropes and the post was implemented by using the seatbelt element, which allows the ropes to slip through a fixed point (node A) acting like a pulley system, as depicted in Fig. 19c. For all the steel-steel contacts involved in the simulation, the dynamic friction coefficient was assumed as 0.1 , and the static friction coefficient was 0.15 [32].

\subsection{Modelling of the full-scale impact tests}

A numerical model of barrier 1500 was built following the above mentioned procedure. The model was successively subjected to SEL and MEL impacts. Before the impact, only gravity load acted on the model so that the net hung down naturally. The coordinates of all nodes as well as the stress and strain data were derived to override the original model, thus enabling the model to contain both initial stress and deflection as in the insitu conditions before to be collided by the block. 

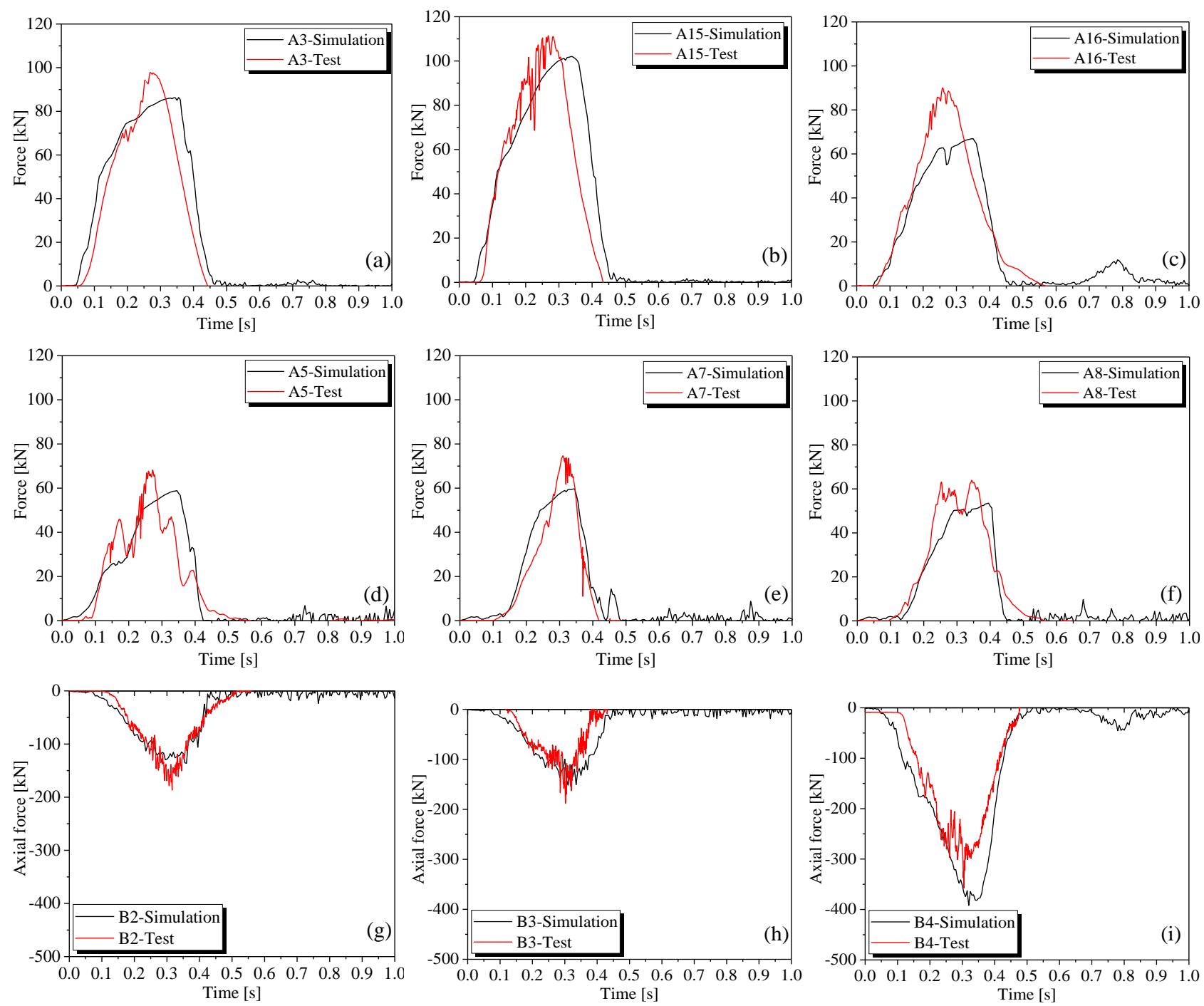

Fig. 20. Comparison of time-histories response between simulation and test results of SEL impact (first launch): (a) A3 load cell; (b) A15 load cell; (c) A16 load cell; (d) A5 load cell; (e) A7 load cell; (f) A8 load cell; (g) B2 strain gauge; (h) B3 strain gauge and (i) B4 strain gauge. For labels of the sensors reference is made to Fig. 9a.

For the first launch at SEL, the block was modeled as a solid rigid element with an initial velocity of $26 \mathrm{~m} / \mathrm{s}$ located just above the wire-ring net. In Fig. 20, all the load cells and strain gauges data (see Fig. 9a for nomenclature) recorded in the full-scale field test are represented and compared with the numerical results (results from malfunctioned devices are not reported). The curves were smoothed by a Savitzky-Golay filter to eliminate the electrical noise. In particular, Fig. 20a-Fig. 20c show the time-history curves of the internal tensile forces near the anchorages of the upper support ropes, while Fig. 20d-Fig. 20f represent the internal force values of the upslope ropes. Figure 20g-Fig. 20i display the axial force of the steel posts derived from the axial strain record, as well as the numerical axial force results extracted from the output data of the simulation. According to the design assumption, the steel posts behave within the elastic range, so that the axial force time-history result was obtained via multiplying the average axial strain records from the gauges on both sides of the web plate by the elastic modulus and cross-sectional area. In general, it can be observed from the comparison that the numerical simulation captures the main trend of the force time-history response, while predicts the peak force with a maximum error equal to $25.6 \%$ that occurs at load cell A16, Fig. 20c. Besides, the longitudinal support ropes are loaded prior to the upslope ropes, so the activation times of the 
force response of load cells on support ropes (Fig. 20a-Fig. 20c) are earlier than those of upslope ropes (Fig. 20d-Fig. 20f). This phenomenon is also well represented by the numerical model, indicating its good performance in reproducing the impact process at different loading stages.
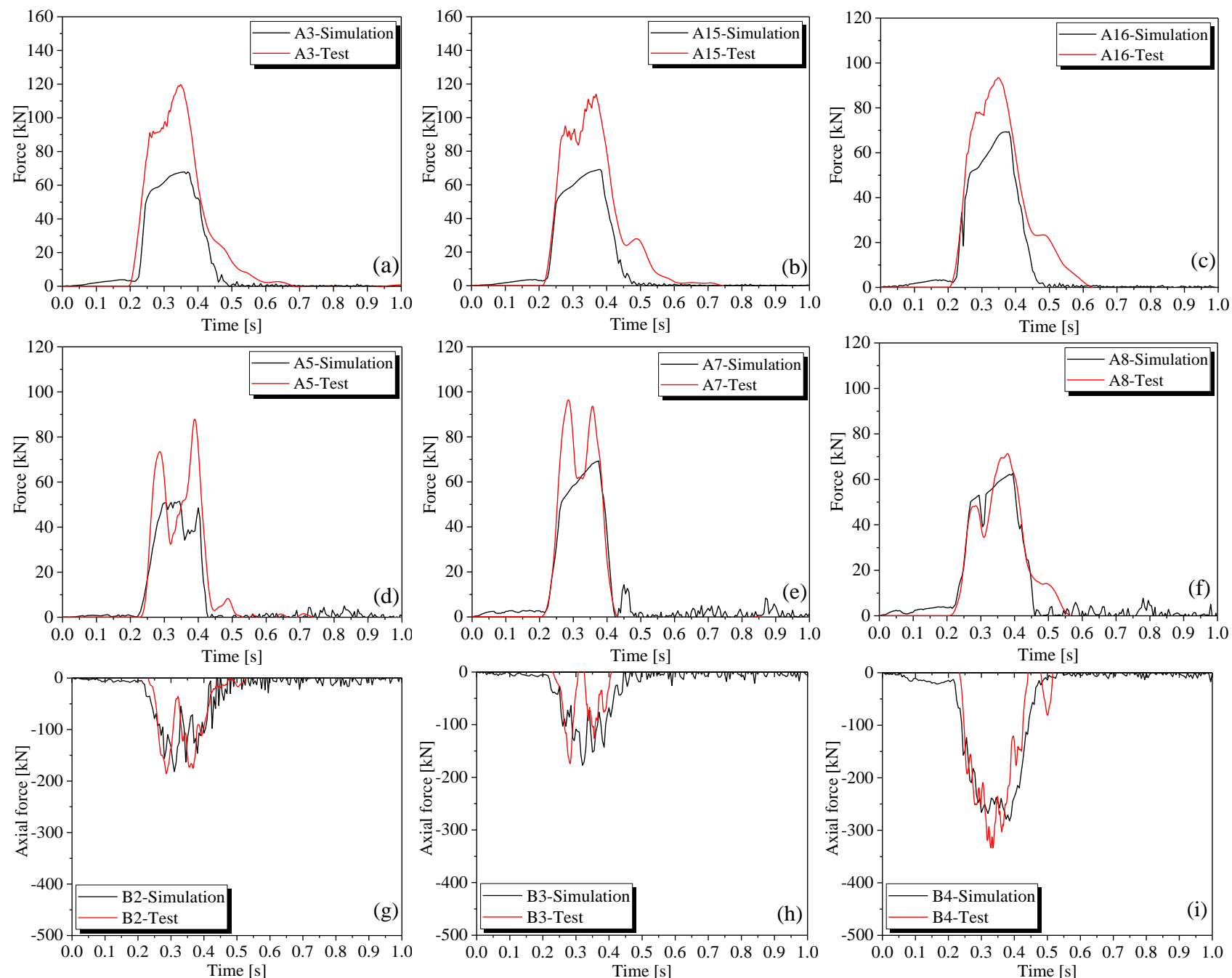

Fig. 21. Comparison of time-histories response between simulation and test results of SEL impact (second launch): (a) A3 load cell; (b) A15 load cell; (c) A16 load cell; (d) A5 load cell; (e) A7 load cell; (f) A8 load cell; (g) B2 strain gauge; (h) B3 strain gauge and (i) B4 strain gauge. For labels of the sensors reference is made to Fig. 9a.

With regard to the second launch at SEL, the barrier structure, after the first launch without any rehabilitation, was subjected to another $500 \mathrm{~kJ}$ impact energy. Accordingly, the coordinates and residual stresses of the deformed numerical model were kept as the initial state for the second launch. In Fig. 21, the experimental and calculated time-history responses at some representative sensors are given. In particular, Fig. 21a-Fig. 21c show the tensile forces recorded by load cell A3, A15 and A16 on the longitudinal support ropes, respectively, and Fig. 21d-Fig.21f show the tensile forces recorded by load cell A5, A7 and A8 on the upslope ropes, respectively, along with the corresponding numerical results. Figure 21g-Fig.21i compare the axial force response recorded by strain gauge B2, B3, and B4, respectively, on the posts with the simulation results. According to these plots, the general trend of the experimental results in the second launch is also well reproduced by the model, revealing that the effectiveness of the numerical approach is validated for the SEL impacts. 
For MEL impact, since the barrier was repaired before the test, an intact numerical model, as the one employed for the first SEL impact, was employed. By comparing the time-histories response between the experiment and simulation in Fig. 22, the good agreement between the results is confirmed. In addition, Fig. 23a and Fig. 23b illustrate the barrier final state of MEL impact in site test and simulation, respectively. In Fig. 23c, the residual height $h_{\mathrm{R}}$ that denotes the minimum distance between the lower and the upper support rope, measured orthogonally to the reference slope after the test without removing the block, is represented as obtained from the numerical simulations.

As stated in Section 2.2, the trajectory of the block in the full-scale tests was captured by the high speed camera. By means of the software Tracker [57], the position-time curve of the block is obtained. In Fig. 24a, the displacement time-history curve is represented together with the numerical result. Velocity and acceleration are calculated automatically by means of the Finite Difference method. In particular, the velocity for a step is defined to be the average velocity over a 2-step interval, and represented in Fig. 24b. The block acceleration is calculated as the second derivative of a parabolic fit over a 4-step interval with the step at the center, red curve in Fig. 24c, and smoothed by a Savitzky-Golay filter, blue curve in Fig. 24c. This procedure for calculating velocity and acceleration ensured a high accuracy of the solution also close to the braking time. The impact force $F$ between the block and the net, obtained from the acceleration record, versus the displacement $S$ in the MEL test is depicted and compared with the calculated curve in Fig. 24d. Through the above comparison analysis, it can be concluded that the proposed numerical model is also suitable for representing the full-scale impact test at MEL.
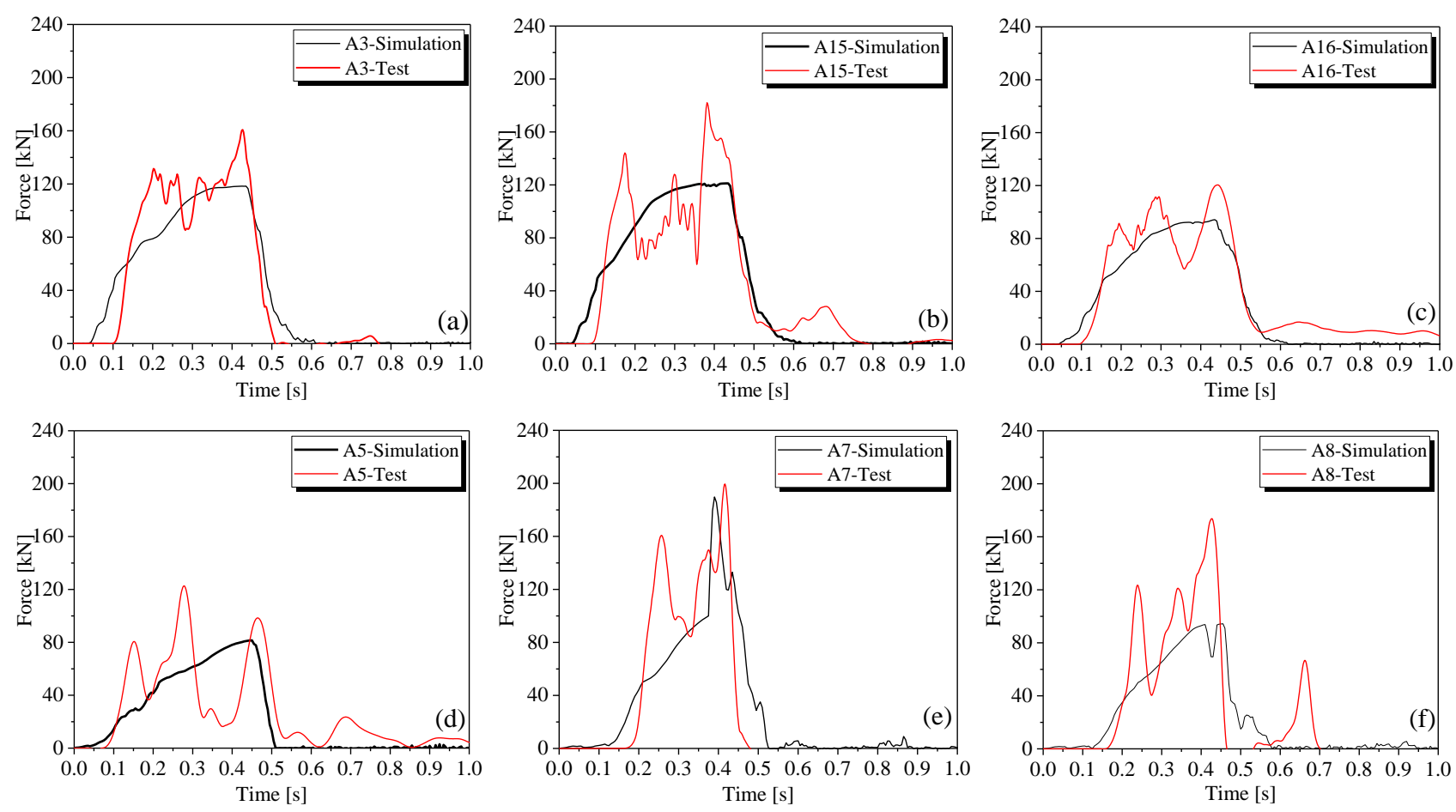

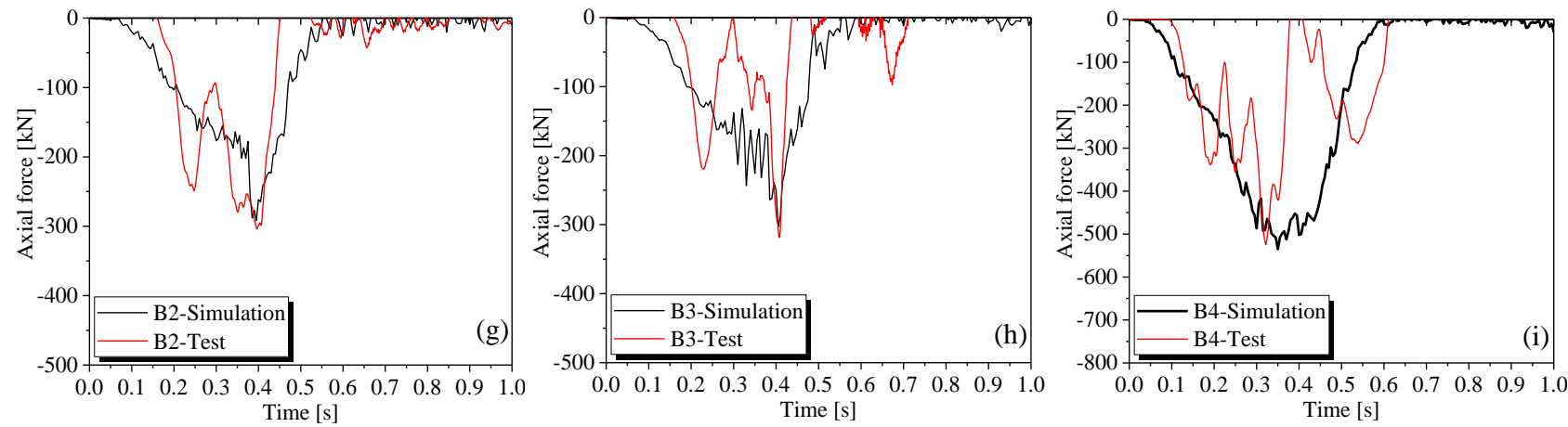

Fig. 22. Comparison of time-histories response between simulation and test results of MEL impact: (a) A3 load cell; (b) A15 load cell; (c) A16 load cell; (d) A5 load cell; (e) A7 load cell; (f) A8 load cell; (g) B2 strain gauge; (h) B3 strain gauge and (i) B4 strain gauge. For labels of the sensors reference is made to Fig. 9a.

Furthermore, to verify the numerical model as a reliable design tool, it is necessary to check the key parameters required in ETAG standard [15], which are used to assess the capacity of the barrier structure. Table 3 lists the parameters measured in the site test, compared with the corresponding data from the numerical calculations. The nominal height $h_{\mathrm{N}}$ is the minimum distance between the upper support rope and the connection line between the bases of the posts, measured orthogonally to the reference slope before the impact. The ratio of $h_{\mathrm{R}}$ to $h_{\mathrm{N}}$ is crucial to judge the test results and to classify the category of the barrier. The maximum elongation $S_{\max }$ is the downslope displacement of the net measured parallel to the reference slope during impact. Even though the calculated ratio of $h_{\mathrm{R}}$ to $h_{\mathrm{N}}$ in the second launch of SEL impact is $15 \%$ lower than the test result, the comparison of the data given in Table 3 reflects a good performance of the numerical model in predicting the key parameters for design.

(a)
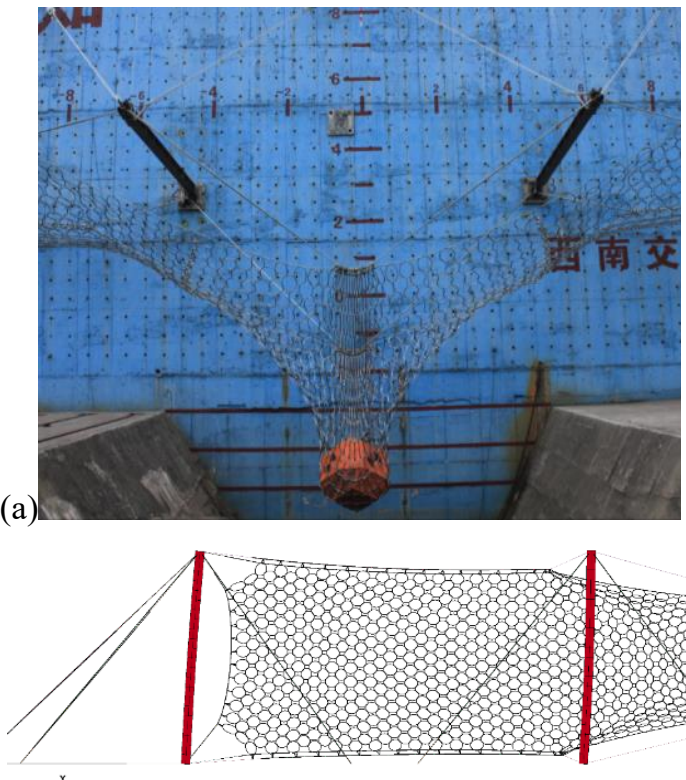

(b)
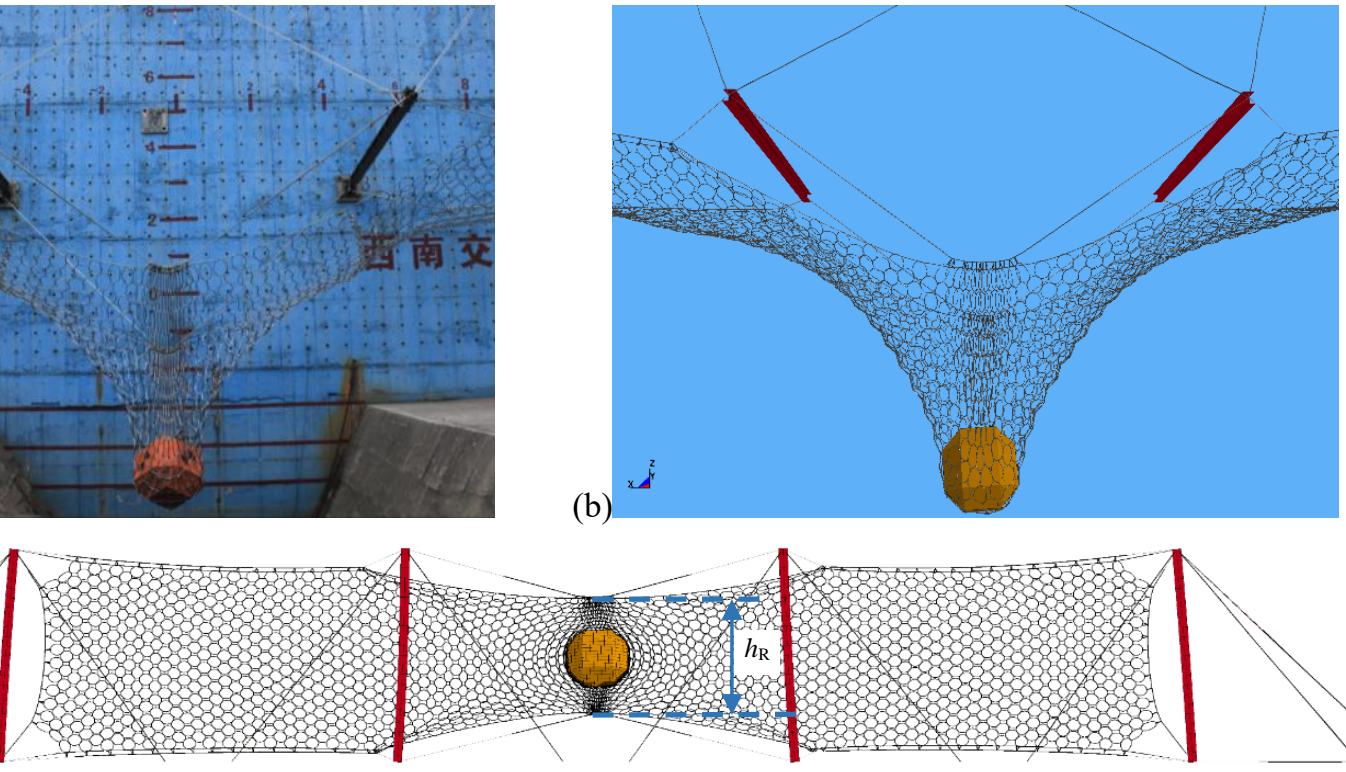

(c) $\quad \mathrm{L}$

Fig. 23. MEL impact results of barrier 1500: (a) in-situ ultimate deformation; (b) numerical ultimate deformation; and (c) numerical residual height. 

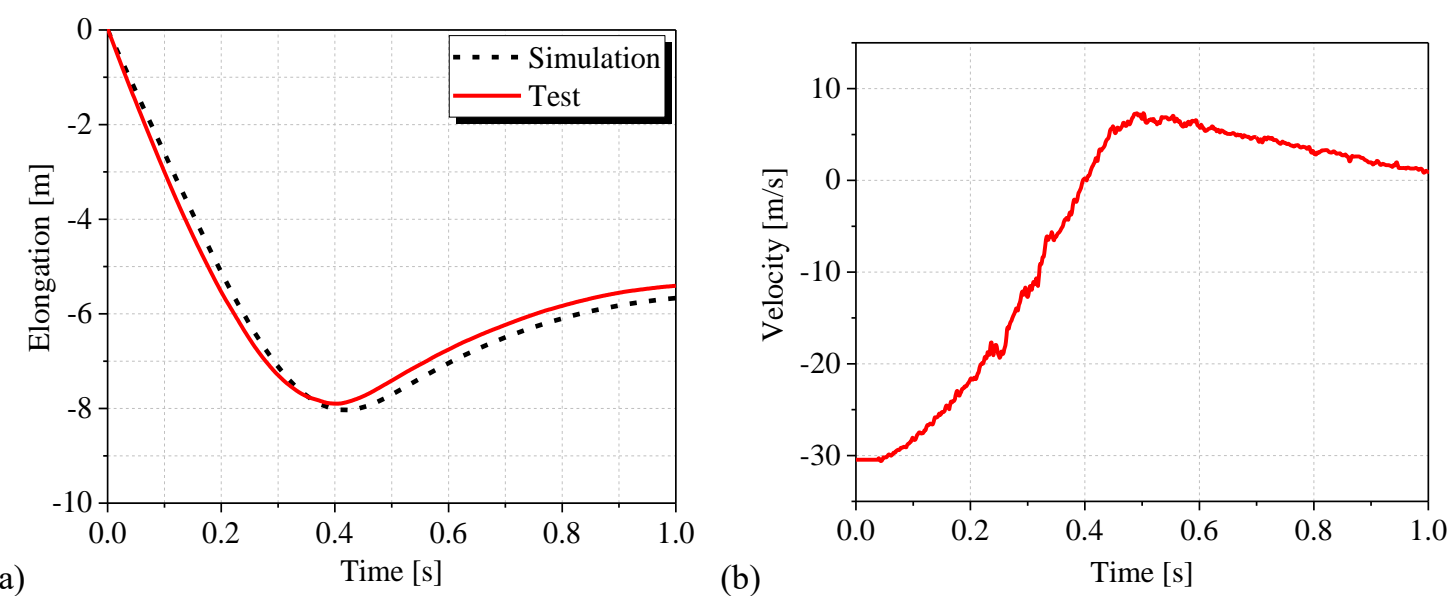

(a)

(b)

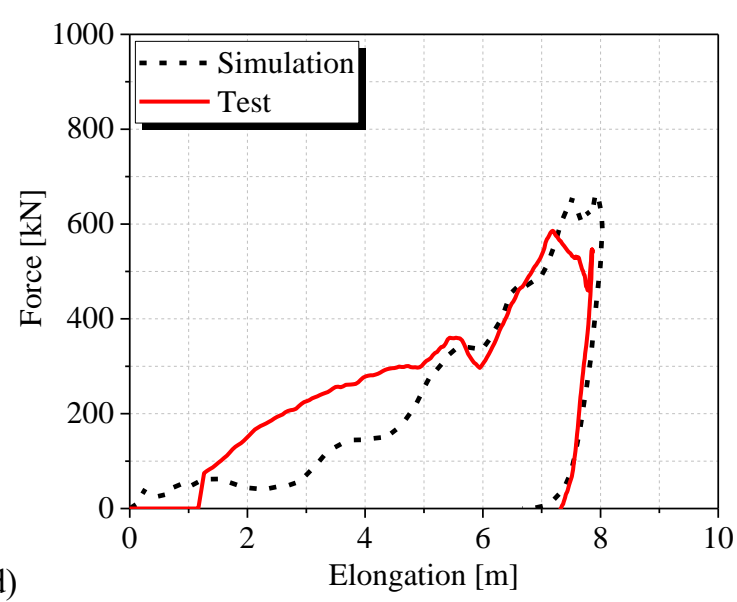

(c)

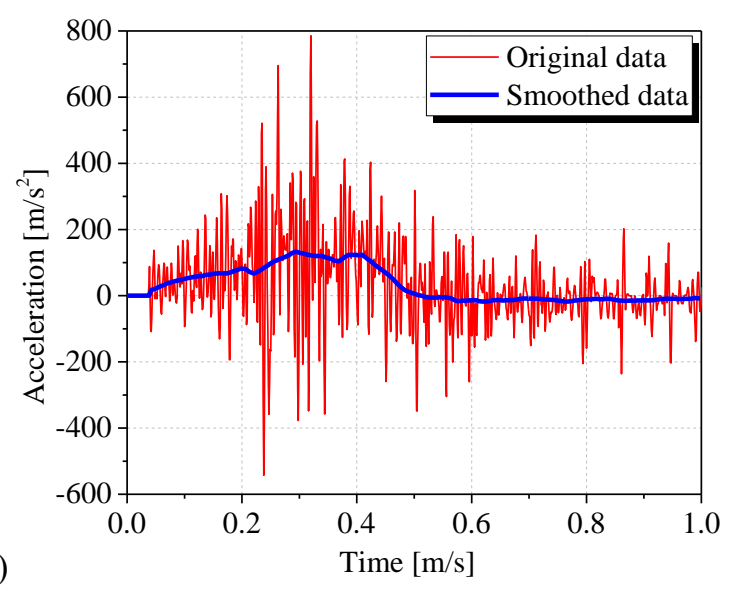

(d)

Fig. 24. MEL impact results of barrier 1500: (a) displacement time-history of the block (test results in red color, simulation results in black color); (b) velocity time-history of the block (test results in red color); (c) acceleration time-

history of the block (test results in red and blue color before and after filter application, respectively); and (d) performance curve of impact force $F$ versus barrier elongation $S$ (test results in red color, simulation results in black color).

Table 3. Comparison of key parameters for design between test and simulation (barrier 1500).

\begin{tabular}{ccccccc}
\hline & \multirow{2}{*}{ Impact } & & $\begin{array}{c}\text { Nominal height } \\
h_{\mathrm{N}}[\mathrm{m}]\end{array}$ & $\begin{array}{c}\text { Residual height } \\
h_{\mathrm{R}}[\mathrm{m}]\end{array}$ & $h_{\mathrm{R}} / h_{\mathrm{N}} \%$ & \multicolumn{2}{c}{ Maximum elongation } \\
$S_{\max }[\mathrm{m}]$
\end{tabular}

\section{ENERGY DISTRIBUTION IN THE ROCKFALL BARRIERS}

In this section, by means of the numerical model of the barrier previously assessed, the energy distribution during impact among the different barrier components is analyzed. Additionally, in order to figure out the energy allocation in barriers of different capacities, numerical models of barriers of nominal energy equal to $750,1000,2000,3000$ and $5000 \mathrm{~kJ}$ were developed. In particular, the role of the wire-ring net and energy dissipating devices is investigated. A formula for deriving the design internal force of the ropes in the different barriers is presented as well.

\subsection{Composition of the total energy}

In the previous section, it was shown how the presented numerical model is reliable in representing the 
dynamic response of a flexible rockfall barrier during the impact. In particular, the main dominant parameters and the energy dissipation of each barrier component were accurately predicted.

The total energy, $E_{\text {total }}$, consumed by the barrier structure during the impact is higher than its nominal energy level, owing to the gravity acting on the block along the impact elongation:

$$
E_{\mathrm{total}}=E_{\mathrm{k} 0}+m g \sin \alpha S_{\max }=\int_{0}^{S_{\max }} F(S) \mathrm{d} S+E_{\mathrm{ks}}
$$

where $E_{\mathrm{k} 0}$ is the initial kinetic energy of the block before the contact with the net, that is always defined as the nominal energy level, $m$ is the block mass, $\alpha$ is angle between the elongation and gravity direction (equal to the slope gradient in the actual projects, equal to $90^{\circ}$ in in-situ tests), $F(S)$ is the impact force between the block and the net, varying with the elongation, $E_{\mathrm{ks}}$ is the kinetic energy of the barrier structure when the impactor is just stopped, as the elongation reaches $S_{\max }$.

According to the energy conservation law, during the process of braking, the total energy is given by the work acted by $F(S)$ while $S_{\max }$ is reached and by the kinetic energy of the barrier structure, $E_{\mathrm{ks}}$. The dissipated energy through the work acted by $F(S)$ along the elongation is equal to the envelop area of the performance curve ( $F$ $S$ curve), which essentially contains two parts, Fig. 24d. The first part is the internal energy of the components $\left(E_{\text {int }}\right)$, consisting of plastic and elastic strain energy, and the other part accounts for the work of movements of the components $\left(E_{\mathrm{rm}}\right)$, such as rotation of the posts and sliding between each part.

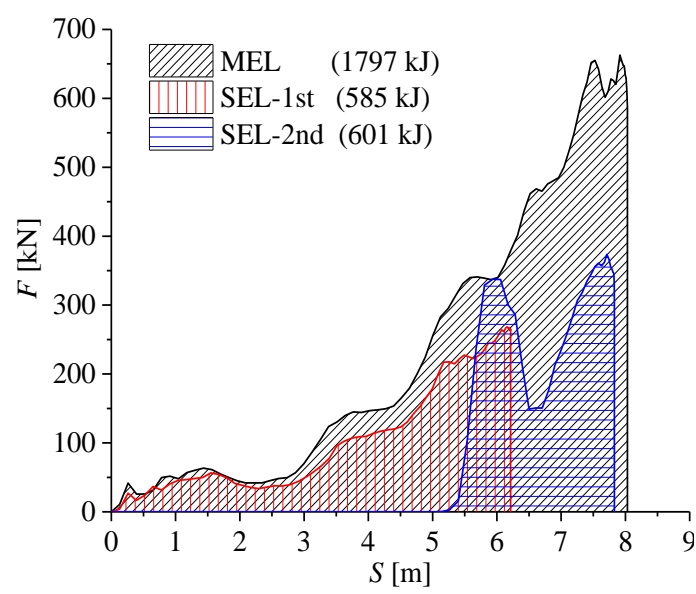

Fig. 25. Force versus elongation of barrier 1500 at MEL, SEL ( $1^{\text {st }}$ launch) and SEL ( $2^{\text {nd }}$ launch $)$ impacts. Shaded areas are the dissipated energy $\left(E_{\mathrm{int}}+E_{\mathrm{rm}}\right)$ as the maximum elongation is reached.

Based on the simulation results, the dissipated energy as the block velocity decreases to zero in the different impacts of barrier 1500 is shown in Fig. 25. The energy values are derived from the numerical solution in terms of envelop area under the force versus elongation curves. The total numerical dissipated energies are divided into different parts as listed in Table 4, which indicates that the greatest part of the total energy is consumed in terms of internal energy, in which the wire-ring net and brake rings play an important role. Besides, the kinetic energy of the barrier $E_{\mathrm{ks}}$ at the moment $S_{\max }$ is reached, is quite low. Conversely, the energy consumed by the component movements $E_{\mathrm{rm}}$ cannot be neglected. As expected, since the impact force is not big enough to fully activate the dissipators in the SEL cases, the energy dissipated by the brake rings is lower with respect to that of the MEL case.

In order to figure out the energy allocation of barriers of different capacities, a series of MEL tests were 
reproduced by means of the proposed numerical approach. The numerical simulations were conducted including barrier prototypes of nominal energy level $E_{\mathrm{N}}$ equal to $750 \mathrm{~kJ}, 1000 \mathrm{~kJ}, 2000 \mathrm{~kJ}, 3000 \mathrm{~kJ}$ and 5000 $\mathrm{kJ}$. According to the numerical results, Fig. 26 depicts how $E_{\text {total }}$ is divided into $E_{\mathrm{ks}}, E_{\mathrm{int}}$ and $E_{\mathrm{rm}}$. It is revealed that, the total energy is always 1.23 times on average greater than the barrier nominal energy. Besides, in all cases, the internal energy $E_{\text {int }}$ of the barriers constitutes the greatest part of the total energy (around 78\% on average), while sliding and other movements consume about $19.4 \%$ of the total energy on average. In addition, the kinetic energy of the structure $E_{\mathrm{ks}}$ only takes up $2.6 \%$ on average of the total energy, so that it can be ignored in design.

Table 4. Total energy distribution of barrier 1500 in the impacts.

\begin{tabular}{cccccc}
\hline \multirow{2}{*}{ Impact } & Energy $[\mathrm{kJ}]$ & $E_{\mathrm{ks}}$ & \multicolumn{2}{c}{$E_{\text {int }}[\mathrm{kJ}]$} & $E_{\mathrm{rm}}$ \\
\cline { 3 - 6 } & {$[\mathrm{kJ}]$} & 52 & 371 & Energy dissipators & Other elastic deformation \\
\hline MEL & $E_{\text {total }}=1849$ & 32 & 136 & 1053 & 70 \\
SEL-1 $^{\text {st }}$ & $E_{\text {total }}=617$ & 44 & 273 & 36 \\
SEL-2 $^{\text {nd }}$ & $E_{\text {total }}=645$ & 44 & 304 & 140 & 29 \\
\hline
\end{tabular}

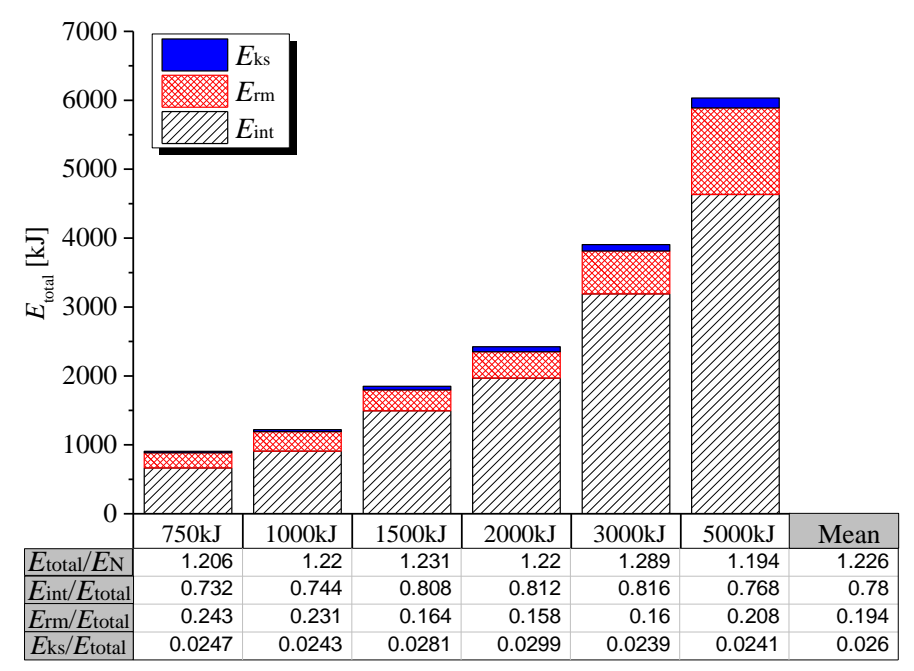

Fig. 26. Dissipated energy by barriers 750, 1000, 1500, 2000, 3000 and 5000 at MEL impact.

With the aim of proposing a reliable and efficient design method, the capacity of the main energy consuming components that include wire-ring net and dissipators, must be no less than the design energy $E_{\mathrm{d}}$. In other words, the barrier structure has to be devised to consume the design energy $E_{\mathrm{d}}$ completely in terms of the internal energy of the net and dissipators, while other energy dissipating ways can be considered as safety reservations. However, regarding the non-negligible role of $E_{\mathrm{rm}}$ as well as the fact that the total energy is higher than the nominal energy, the design energy $E_{\mathrm{d}}$ can be conservatively represented by the nominal energy $E_{\mathrm{N}}$ as follow:

$$
E_{\mathrm{d}}=\gamma_{\mathrm{t}}\left(1-\gamma_{\mathrm{rm}}\right) E_{\mathrm{N}} \approx E_{\mathrm{N}}
$$

where $\gamma_{\mathrm{t}}$ denotes the magnification coefficient of the total energy and $\gamma_{\mathrm{rm}}$ denotes the proportional coefficient of $E_{\mathrm{rm}}$, equal to 1.226 and 0.194 , according to Fig. 26, respectively.

\subsection{Energy allocation of the wire-ring net}

As one of the most essential energy dissipating components, the contribution of wire-ring net has to be 
forecasted in design. According to the simulation results, Table 5 displays the energy actually consumed by different wire-ring nets (R5, R7, R9, R12, R16 and R19) in barrier structures with different nominal energy levels. In the table, $E_{\text {un }}$ denotes the energy dissipating capacity of a net panel unit ( $3 \mathrm{~m} \times 3 \mathrm{~m}$ ), subjected to an out-of-plane test. It is indicated that, with the increase of the winding numbers of the wire-ring, the maximum capacity of the net panel unit grows. In the other columns of the table, the dissipated energy of wire-ring nets with different winding number in barriers of different capacities subjected to MEL impacts is listed as well. Where the results are not reported, the corresponding barrier fails. It can be noted that the energy dissipating value of the net in one specific barrier does not keep rising up, since a greater force, that is supposed to act on the higher winding net, leads to a fuller stroke of the energy dissipators so that the dissipated energy by the net decreases.

Table 5. Dissipated energy by net panel units subjected to out-of-plane loads $\left(E_{\mathrm{un}}\right)$ and dissipated energy of wire nets in barriers of different nominal energy levels at MEL impact.

\begin{tabular}{|c|c|c|c|c|c|c|c|}
\hline Wire-ring net & $E_{\text {un }}[\mathrm{kJ}]$ & $750 \mathrm{~kJ}$ & $1000 \mathrm{~kJ}$ & $1500 \mathrm{~kJ}$ & $2000 \mathrm{~kJ}$ & $3000 \mathrm{~kJ}$ & $5000 \mathrm{~kJ}$ \\
\hline R5 & 42.5 & & & & & & \\
\hline R7 & 63.8 & 200 & & & & & \\
\hline R9 & 99.2 & 219.4 & 299.7 & 342 & & & \\
\hline $\mathrm{R} 12$ & 141.6 & 192.4 & 317.5 & 370.7 & 442.3 & & \\
\hline R16 & 224.4 & 148.8 & 288.5 & 329.7 & 435.7 & 705.8 & \\
\hline R19 & 277.9 & 116.8 & 245.1 & 290.3 & 412.4 & 644.2 & 862.8 \\
\hline
\end{tabular}

In order to evaluate the role of the net in dissipating the energy, a parameter $\alpha$, that represents the ratio between the dissipated energy by the net in barrier structures and the energy dissipating capacity of the corresponding net panel unit $E_{\text {un, }}$, is introduced. The data from Table 5 are used to calculate the ratio $\alpha$, illustrated by scatter points in Fig. 27. It is revealed that by fitting the scatter points for each specific winding number of the wirering net, $\alpha$ increases as the nominal energy level $E_{\mathrm{N}}$ becomes bigger and can be expressed as linear formulas with low dispersion. Thus, for the five types of wire-ring net listed in Table 5, the linear equations are expressed as follow:

$$
\alpha=\left\{\begin{array}{c}
4.18 E_{\mathrm{N}} \times 10^{-3}, \text { for R7 } \\
2.58 E_{\mathrm{N}} \times 10^{-3}, \text { for R9 } \\
1.72 E_{\mathrm{N}} \times 10^{-3}, \text { for R12 } \\
1.03 E_{\mathrm{N}} \times 10^{-3}, \text { for R16 } \\
0.675 E_{\mathrm{N}} \times 10^{-3}, \text { for R19 }
\end{array} \quad \text { while } \alpha \leq 3.5\right.
$$

Based on the maximum $\alpha$ values found for the different nets, the upper bound of $\alpha$ is defined to be 3.5 . Besides, for the irregular wire-ring types, such as R6, R8, R14, etc., the corresponding factor $\alpha$ can be obtained from Eq. (5) by means of interpolation according to the winding number. 


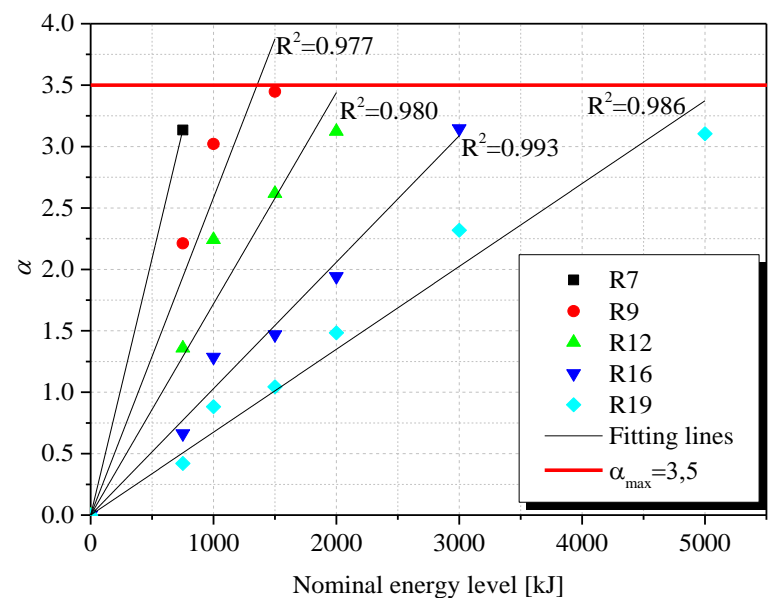

Fig. 27. Factor $\alpha$ for wire-ring nets in barriers of different nominal energy levels at MEL impact.

\subsection{Energy allocation of the energy dissipating devices}

All the energy dissipators in the barriers are mounted on the wire ropes. The dissipators on the different ropes are activated at different moments during the impact. However, the dissipators on the same rope start to work simultaneously, so that they can be considered as an integrated energy dissipating assembly.

Through the numerical simulations, Fig. 28 displays the dissipated energy allocation among different ropes (labelled as type 1 6) for each nominal energy level at MEL impact. Each symbol denotes the sum of the dissipated energy by each brake ring mounted on one specific rope. Considering the distribution of the points in the figure, it is revealed that the energy absorbed by each dissipator assembly on each type of rope grows as the nominal energy level increases. The slopes of the fitting lines $k_{i}$ (with $i=1 . .6$ ) denote the ratio between the dissipated energy for a dissipator assembly to the nominal energy level. The dissipators on the lower major support rope ( 3 in the figure) absorb up to the $21.3 \%$ of the nominal energy. Three types of rope (1 3) account for nearly $50 \%$ of the nominal energy level in all, and the other three (4 6) take $29.4 \%$ altogether.

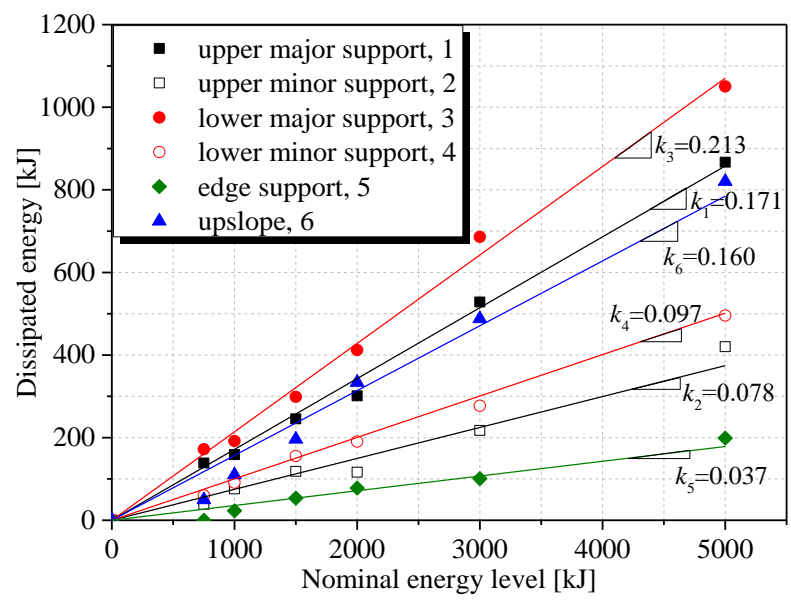

Fig. 28. Dissipated energy distribution among the dissipator assemblies mounted on the different ropes in barriers of different nominal energy levels at MEL impact.

According to the ratio $\left(k_{i}\right)$ represented in Fig. 28, the energy supposed to be absorbed by all dissipators can be allocated to each type of rope via a coefficient $\eta_{i}$ defined as

$$
\eta_{i}=\frac{k_{i}}{\sum k_{i}}, \text { with } i=1 . .6 \text {. }
$$


Coefficients $\eta_{i}$ for the brake ring assembly on the different types of rope are listed in Table 6. In other words, coefficient $\eta_{i}$ represents the dissipated energy percentage by the $i$-th dissipator assembly (mounted on a specific rope) with respect to the total energy absorbed by all the dissipator assemblies in a barrier.

Table 6. Coefficient $\eta$ for the dissipator assemblies mounted on the different ropes.

\begin{tabular}{|c|c|c|c|c|c|}
\hline $\begin{array}{c}\eta_{1} \\
\text { upper major } \\
\text { support rope }\end{array}$ & $\begin{array}{c}\eta_{2} \\
\text { upper minor } \\
\text { support rope }\end{array}$ & $\begin{array}{c}\quad \eta_{3} \\
\text { lower major } \\
\text { support rope }\end{array}$ & $\begin{array}{c}\eta_{4} \\
\text { lower minor } \\
\text { support rope }\end{array}$ & $\begin{array}{c}\eta_{5} \\
\text { edge support rope }\end{array}$ & $\begin{array}{c}\eta_{6} \\
\text { upslope rope }\end{array}$ \\
\hline $22.6 \%$ & $10.3 \%$ & $28.2 \%$ & $12.8 \%$ & $4.9 \%$ & $21.2 \%$ \\
\hline
\end{tabular}

\subsection{Prediction of the rope internal forces}

The wire ropes are one of the most crucial components in barrier structures, since their failure could directly lead to the collapse of the whole system, as it was observed in field investigations [6]. As a consequence, an adequate safety margin is necessary for the ropes in design.

Figure 29 collects the peak forces, $F_{\mathrm{m}}$, in the different ropes evaluated numerically for the different barriers at MEL test. In particular, for those barrier models with high nominal energy level, more than one rope was employed for each kind of support rope or upslope rope in case of excessive loadings. Thus, the arrangement of the brake rings can be considered as parallel connection, so that the peak forces summarized in Fig. 29, generally, grow as the nominal energy level increases. Furthermore, the peak force of the major support ropes, upslope ropes and side anchor ropes grow much faster with respect to that of the minor support ropes and edge support ropes. Moreover, peak forces are very close between the upper major (solid squares) and lower major support (solid circles) ropes as well as between the upper minor (empty squares) and lower minor support (empty circles) ropes, owing to the longitudinal symmetry of the structure. Among all upslope ropes, the peak forces given in Fig. 29 (blue triangles) are derived from the ones connected to the middle functional module, that are much larger than those from the ones connected to the lateral modules.

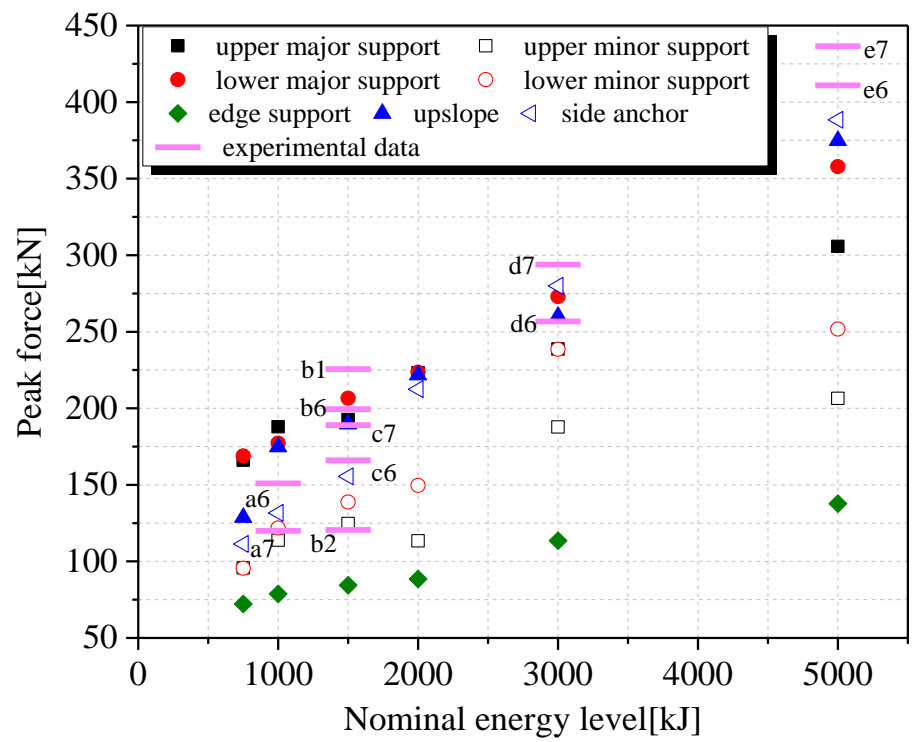

Fig. 29. Peak forces, $F_{\mathrm{m}}$, of the ropes in barriers of different nominal energy levels and from literature data (dash symbol): a6, a7 - peak forces of upslope and side anchor ropes in the $1000 \mathrm{~kJ}$ test from [51]; b1, b2, b6 - peak forces of 
upper major, upper minor and upslope ropes in the $1500 \mathrm{~kJ}$ test presented in this paper; $\mathrm{c} 6$, c7 - peak forces of upslope and side anchor ropes in $1500 \mathrm{~kJ}$ test from [7]; d6, d7 - peak forces of upslope and side anchor ropes in $3000 \mathrm{~kJ}$ test from [33]; e6, e7 - peak forces of upslope and side anchor ropes in $5000 \mathrm{~kJ}$ test from [20].

Experimental data derived from different full-scale impact tests taken from literature are reported as well in Fig. 29 with a dash. It is revealed that the predicted peak forces match well with those experimentally found, proving that the simulation results can be employed for design.

Based on the above predicted peak forces $F_{\mathrm{m}}$ shown in Fig. 29, an expression for the design forces of the ropes $F_{\mathrm{dr}}$ is derived as:

$$
F_{\mathrm{dr}}=\gamma_{1} \gamma_{2} F_{\mathrm{m}}
$$

where $\gamma_{1}$ is a reserve coefficient for asymmetrical impact in case that the impact point is not at the center of the module. Based on numerical analyses, a value equal to 2.0 for all the ropes is employed which provides reliable margin ratio. Parameter $\gamma_{2}$ is a reserve coefficient for strength reduction caused by bending of the rope. It is known that the cross-section area for bearing the tensile force decreases as the rope bends, and as a consequence, a strength reduction ratio for the ropes with the most common dimensions used in the barrier structure is determined [58], which is taken equal to $15 \%$. Hence, the value of $1 / 0.85$ is employed conservatively for coefficient $\gamma_{2}$. However, some ropes do not bend during the impact process, so $\gamma_{2}=1.18$ for the major and minor support ropes as well as the edge support ropes, while $\gamma_{2}=1.0$ for the remaining ropes.

The design forces $F_{\mathrm{dr}}$ for the ropes corresponding to nominal energy levels at intervals of $1000 \mathrm{~kJ}$ are listed in Table 7, and the values for other energy levels can be calculated by means of interpolation. Besides, due to the longitudinal symmetry of the structure, the upper and lower support ropes are not distinguished in the table, only major and minor support ropes are presented herein.

Table 7. Suggested design values for internal forces $F_{\mathrm{dr}}[\mathrm{kN}]$ of steel wire ropes in barriers of different nominal energy levels.

\begin{tabular}{|c|c|c|c|c|c|}
\hline & \multicolumn{5}{|c|}{ Nominal energy levels } \\
\hline & $1000 \mathrm{~kJ}$ & $2000 \mathrm{~kJ}$ & $3000 \mathrm{~kJ}$ & $4000 \mathrm{~kJ}$ & $5000 \mathrm{~kJ}$ \\
\hline Major support rope & 450 & 530 & 650 & 750 & 850 \\
\hline Minor support rope & 290 & 360 & 560 & 580 & 600 \\
\hline Edge support rope & 190 & 210 & 270 & 300 & 330 \\
\hline Upslope rope & 350 & 450 & 520 & 640 & 750 \\
\hline Side anchor rope & 270 & 430 & 560 & 670 & 780 \\
\hline
\end{tabular}

\section{DESIGN METHOD FOR ROCKFALL BARRIERS BASED ON ENERGY ALLOCATION}

In this section, the design approach based on energy allocation is presented. The design approach provides that each main component of the barrier (wire-ring net and brake rings) is chosen as a function of the dissipated energy that is designed to absorb.

The design procedure is applied to a barrier prototype of nominal capacity of $3500 \mathrm{~kJ}$ and finally assessed by means of a full-scale test carried out in the artificial site located in Xinjin County (Sichuan, China).

\subsection{Design process}

The structural design mainly involves the selection of the number and size of barrier components once energy distribution and peak forces have been predicted. Referring to the flow chart represented in Fig. 30, the main 
steps of the proposed design process of rockfall barriers are:

(1) a wire-ring net is selected according to the design energy $E_{\mathrm{d}}$ of the barrier that is considered to be equal to the nominal energy $E_{\mathrm{N}}$ as expressed in Eq. (4). The linear fitting lines in Fig. 27, intersected by a vertical line corresponding to the design energy $E_{\mathrm{d}}$, detect the wire-ring nets that can be selected;

(2) with reference to $E_{\text {un }}$ in Table 5 and Eq. (5), the energy absorbed by the selected net, that is expressed as $\alpha E_{\text {un }}$, can be calculated. The remaining part of the design energy is allocated to the dissipators on each rope, governed by:

$$
E_{\mathrm{ed}, i}=\eta_{i}\left(E_{\mathrm{d}}-\alpha E_{\mathrm{un}}\right), \text { with } i=1 . .6 .
$$

(3) when arranging the dissipators in each rope, except the ones on upslope ropes $(i=6)$, all the dissipators should be set symmetrically with respect to the transverse vertical plane, that means the energy dissipating values obtained by Eq. (8) should be halved for each lateral side.

It is worthy to note that, according to the simulation results and to Fig. 28 , of the $16 \%$ of the total energy dissipated by the dissipators mounted on the eight upslope ropes $(i=6)$, the $85 \%$ is dissipated by the ones on the four upslope ropes connected to the middle functional module and the remaining $15 \%$ is absorbed by the ones on the four upslope ropes connected to the lateral modules. In the design process, the brake rings on the upslope ropes are designed as they are all connected to the central module, not considering the difference between central and lateral ones. Thus, the energy dissipating value $E_{\text {ed, } 6}$ multiplied by 0.85 , is allocated to the upslope ropes dividing it equally.

If more than one dissipator is required for a rope, the serial connection is recommended for improving the deformability of the whole structure. Otherwise, when the total elongation of the system is required to be not large, the parallel connection can be employed. Moreover, a serial-parallel hybrid connection can also be adopted. In the case of either connection measures, the activation force of the dissipator assembly should be no more than $50 \%$ of the breaking force of the rope, to avoid the rupture of the rope caused by the dynamic impulse [56] and to ensure the dissipator assembly to be activated smoothly;

(4) the steel wire ropes are determined by selecting the specification, diameter, number and the nominal breaking force, according to Table 7. 


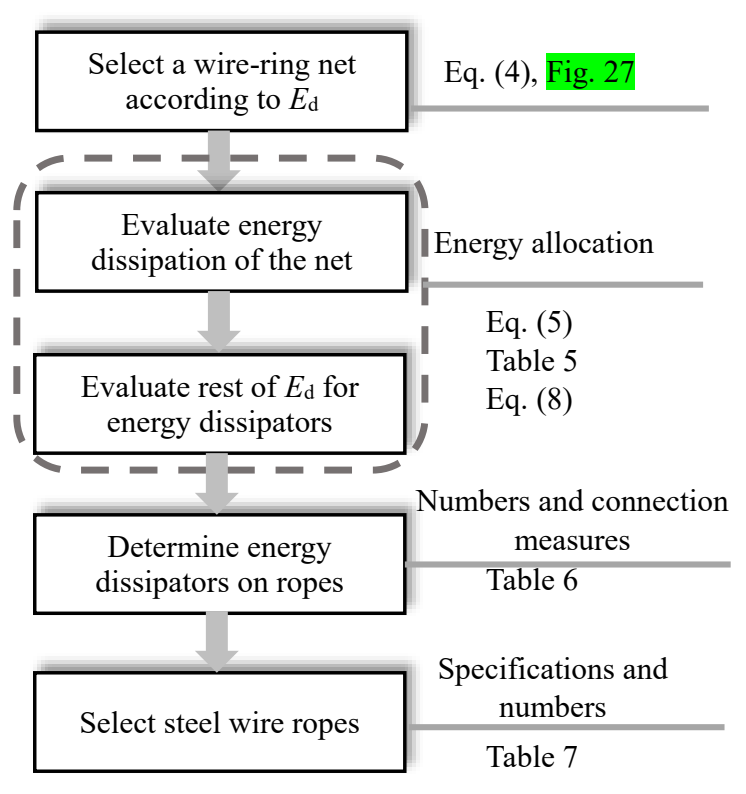

Fig. 30. Flow chart of the proposed design method.

With regard to the posts, lateral buckling that would result in a dramatic reduction of the residual height of the structure should be rigorously avoided. This damage mode is mainly caused by the additional bending moments from the attached ropes and the pedestals. The actions from all the ropes need to concentrate in one point to prevent producing a moment, and a smooth sliding of the support ropes needs to be ensured to avert an unexpected transverse load due to a sudden seizing up [59,60]. Besides, a proper rotational space for the post foot is necessary to release the moment. However, large cross-section and/or add stiffers along the post length can improve the bending rigidity of the post, which is recommended for barriers with high design energy $E_{\mathrm{d}}$.

\subsection{Experimental assessment of the design method}

To verify the proposed design approach, a barrier structure with nominal energy level of $3500 \mathrm{~kJ}$ is designed according to above described method. The experimental prototype still consists of three functional modules, the length and height of each module is $10.0 \mathrm{~m}$ and $6.3 \mathrm{~m}$, respectively. The corresponding full-scale impact test is carried out in another artificial site located in Xinjin County (Sichuan, China). With respect to the test site in Guanghan city, the RC reaction wall has larger dimensions, with a length of $60.5 \mathrm{~m}$ and a height of 17.5 $\mathrm{m}$, and a cantilever crane is employed as lifting system instead of the travelling portal crane, as shown in Fig. $31 \mathrm{a}$. A block with a weight of $11013.5 \mathrm{~kg}$ is released from a height of $32.5 \mathrm{~m}$ to produce $3500 \mathrm{~kJ}$ impact energy.

Table 8. Main components of barrier 3500 determined according to the proposed design method.

\begin{tabular}{|c|c|c|c|c|}
\hline & Component & $\begin{array}{c}\text { Specification } \\
{[\mathrm{mm}]}\end{array}$ & $\begin{array}{l}\text { Design } \\
\text { values }\end{array}$ & Amount \\
\hline & Wire-ring net & $\mathrm{R} 19 / 3 / 300$ & $656.5 \mathrm{~kJ}$ & 1 \\
\hline \multirow{6}{*}{ Dissipator } & upper major support $\left(\mathrm{E}_{\mathrm{ed}, 1}\right)$ & \multirow{6}{*}{$\begin{array}{l}\text { Brake ring } \\
\varphi 402 / 42 \times 6\end{array}$} & $642.6 \mathrm{~kJ}$ & 16 (8 for each lateral side) \\
\hline & lower major support $\left(\mathrm{E}_{\mathrm{ed}, 3}\right)$ & & $801.9 \mathrm{~kJ}$ & 16 ( 8 for each lateral side) \\
\hline & upper minor support $\left(\mathrm{E}_{\mathrm{ed}, 2}\right)$ & & $292.9 \mathrm{~kJ}$ & 12 ( 6 for each lateral side) \\
\hline & lower minor support $\left(E_{\mathrm{ed}, 4}\right)$ & & $364.0 \mathrm{~kJ}$ & 12 ( 6 for each lateral side) \\
\hline & edge support $\left(\mathrm{E}_{\mathrm{ed}, 5}\right)$ & & $139.3 \mathrm{~kJ}$ & 4 (2 for each lateral side) \\
\hline & upslope $\left(\mathrm{E}_{\mathrm{ed}, 6}\right)$ & & $602.8 \mathrm{~kJ}$ & 24 (3 for each rope) \\
\hline Wire rope & upper major support & $6 \times 19 s+I W R$ & $700 \mathrm{kN}$ & $3 \varphi 22$ \\
\hline
\end{tabular}




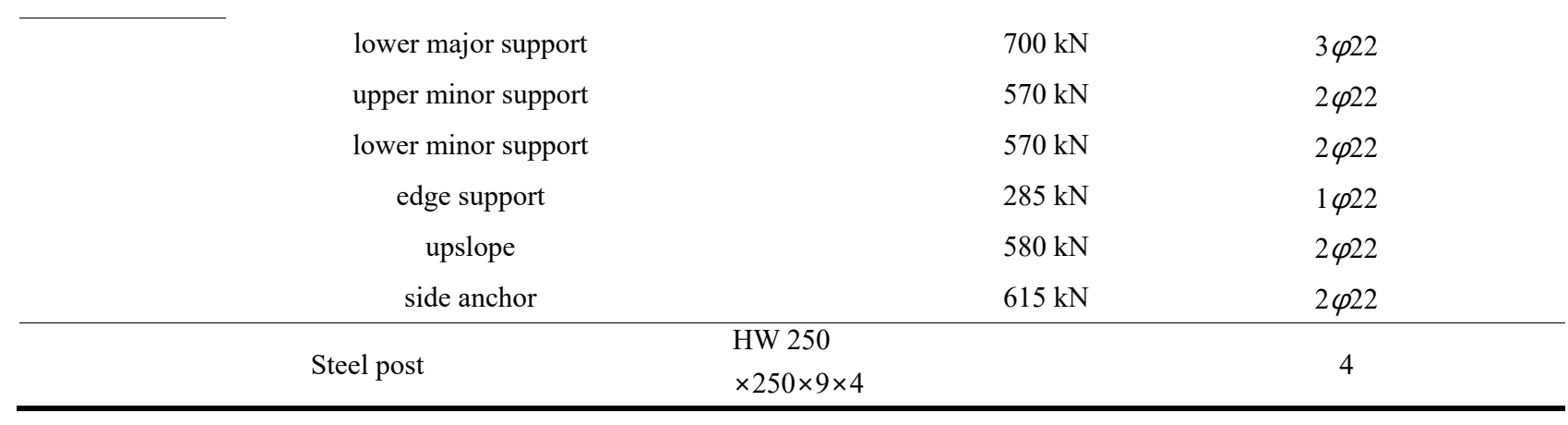

Following the flow chart in Fig. 30, first a wire-ring net has to be selected. Based on Fig. 27, only R19 steel wire-ring net can be chosen for barrier 3500 . The energy capacity of the selected wire-ring net panel unit $E_{\text {un }}$ is $277.9 \mathrm{~kJ}$ as given in Table 5, and $\alpha$ is equal to 2.363, Eq. (5). Thus, the design value of dissipated energy $\alpha E_{\text {un }}$ of $\mathrm{R} 19$ net is $656.5 \mathrm{~kJ}$. The remaining energy of $2843.5 \mathrm{~kJ}$ should be allocated to the dissipators according to Eq. (8). Since the design capacity of the adopted brake ring is $50 \mathrm{~kJ}$, as introduced in Section 3.2, the amount of energy that has to be dissipated for each type of rope can be easily calculated. In addition, the connection measure of the dissipators can be chosen according to their number.

Considering the lower major support rope as an example, the minimum number of required brake rings according to the proposed strategy is obtained as:

$$
\begin{gathered}
i=3 \text { (lower major support rope) } \\
\left.\eta_{3}=28.2 \% \text { (Table } 6\right) \\
E_{\mathrm{d}, 3}=\eta_{3}\left(E_{\mathrm{d}-}-\alpha E_{\mathrm{un}}\right)=801.9 \mathrm{~kJ}
\end{gathered}
$$

$E_{\mathrm{d}, 3}$ is the energy that has to be dissipated by the brake rings on the lower major support rope. Since each brake has a design capacity of $50 \mathrm{~kJ}$, the minimum number of required brake rings is 16 , thus 8 brake rings are set for each lateral side. The serial-parallel hybrid connection is chosen for this dissipator assembly. With regard to each upslope rope on which three brake rings are required at least, a parallel connection measure is adopted. Subsequently, the design values for the peak forces of ropes $F_{\mathrm{dr}}$ are obtained with reference to Table 7 . For the sake of convenience in manufacturing, a uniform diameter of $22 \mathrm{~mm}$ (type $6 \times 19 \mathrm{~s}+\mathrm{IWR}$, strength grade 1870 $\mathrm{MPa}$ ), is selected preliminarily for all steel wire ropes. According to code [61], the breaking force of the rope is $322 \mathrm{kN}$, then the amount of ropes for each type can be determined.

Regarding the posts, a pure axial compression status rather than a compression-bending one should be ensured as far as possible by means of construction measures. The critical stability capacity was determined by the simulations, to select the proper cross-section type and area.

Table 8 lists the details of components determined by the proposed method. Symbol 3/300 for the wire-ring net in the table denotes that the cross-sectional diameter of a single wire is $3 \mathrm{~mm}$ and the diameter of the ring is $300 \mathrm{~mm}$. In particular, considering the longitudinal symmetry of the structure, the number of brake rings finally mounted on the support ropes depends on the larger one between the upper and lower ropes.

Figure $31 \mathrm{~b}$ shows the ultimate deformation of barrier 3500 after the MEL impact. The maximum elongation reached by the structure was $8.6 \mathrm{~m}$ that is lower with respect to the numerical result equal to $9.8 \mathrm{~m}$, while the residual height was $3.52 \mathrm{~m}$ that is close to the numerical result equal to $3.61 \mathrm{~m}$. Figures $31 \mathrm{c}$ and $31 \mathrm{~d}$ display 
the brake rings on the support ropes before and after the impact, respectively. It can be seen that the majority of the brake rings were activated, but near half of them did not reach the full stroke. Figures $31 \mathrm{e}$ and $31 \mathrm{f} \mathrm{show}$ the brake rings on the upslope ropes connected to the middle module before and after the impact, respectively. All brake rings in the figure were activated: three brake rings were fully stretched while other three just ran $1 / 3$ of the full stroke.

Figure 32 compares the energy dissipated by the different components that are expected to absorb all the design energy $E_{\mathrm{d}}$, among the simulation, the full scale test and the design. Besides, the actual capacity of selected dissipator assemblies is also presented (green dashed line), calculated as the minimum design value of dissipated energy of each brake defined equal to $50 \mathrm{~kJ}$ according to the procedure presented in Section 3.2, multiplied for the number of brakes in each assembly. Except for the consumed energy by the wire-ring net, that in the test cannot be directly obtained, all the energy absorbed through the dissipators in the test is determined by measuring the elongation of the brake rings. It should be pointed out that the obtained test values depicted in the figure (checked columns) are equivalent values since they are derived from the forcedisplacement curve in Fig. 18. It is indicated that all design values (dashed blue columns) are higher than test results (checked red columns), despite not too overestimated, so that the proposed energy allocation is efficient as well as safe.

(a)

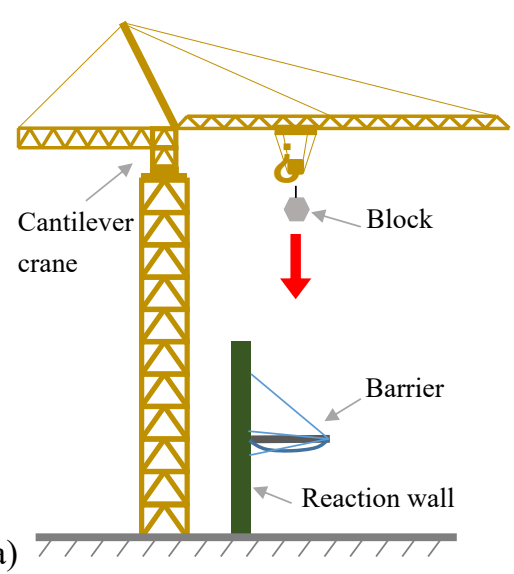

(b)

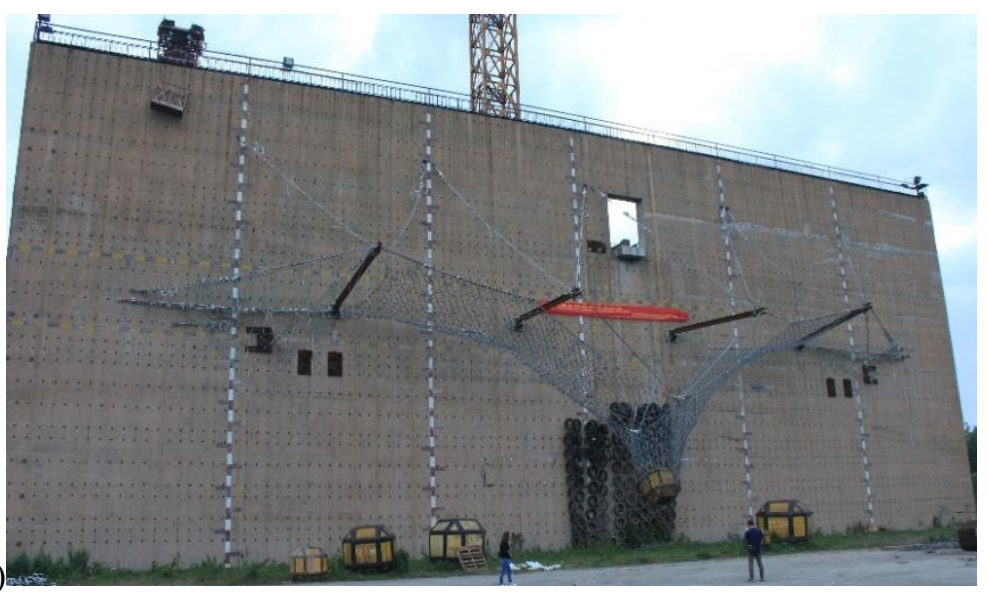

(c)

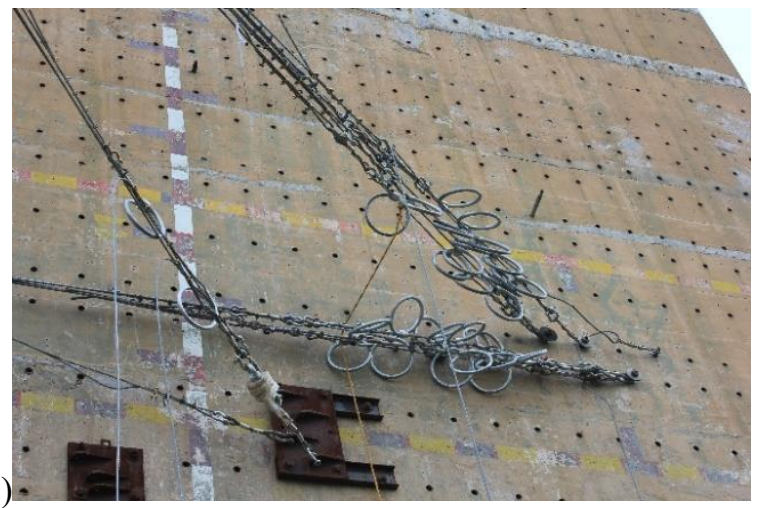

(d)

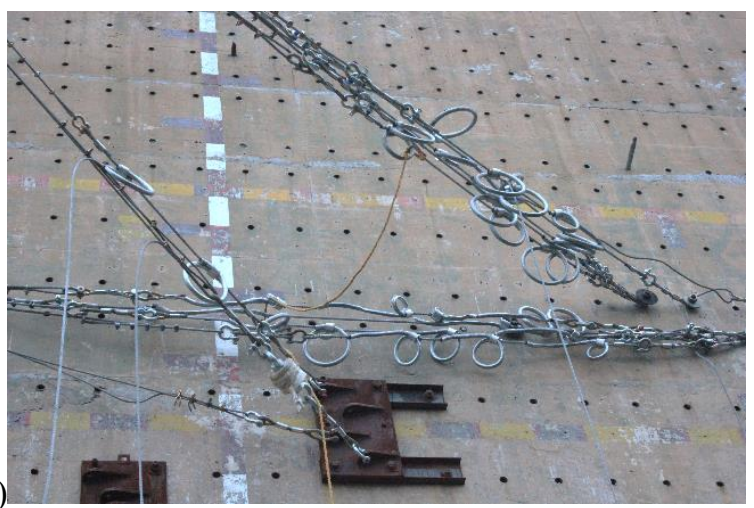



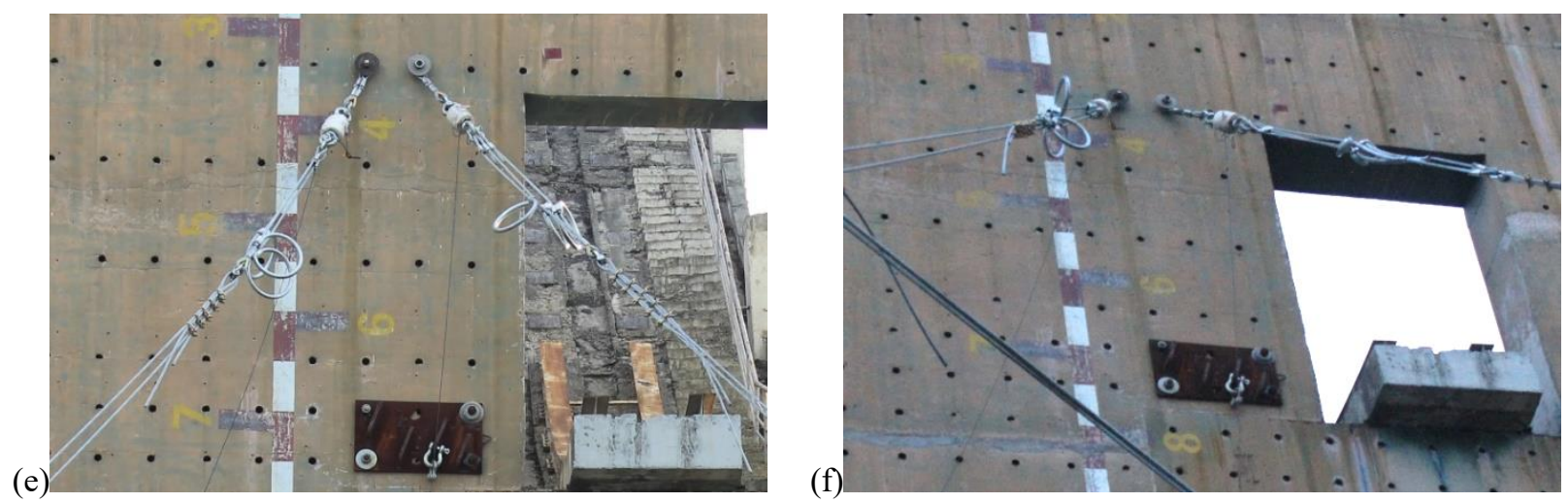

Fig. 31. Experimental result of the MEL impact of barrier 3500: (a) schematic view of the artificial test site in Xinjin (Sichuan, China); (b) in-situ ultimate deformation; brake rings on support ropes (c) before the impact and (d) after the impact; brake rings on upslope ropes (e) before the impact and (f) after the impact.

Additionally, from the figure it can be seen that the total capacity of the dissipator assembly on all the eight upslope ropes (in the figure indicated as 'upslope') is much bigger than the design demand as well as the test data. This is mainly due to the fact that the design value depends on the experimental condition which only allows the impact to take place in the middle module. In particular, the energy dissipation of the brake rings on the four upslope ropes connected to the middle module (in the figure indicated as 'upslope-middle') between the design values and test data is very close, confirming the high cost-effectiveness of the proposed method.

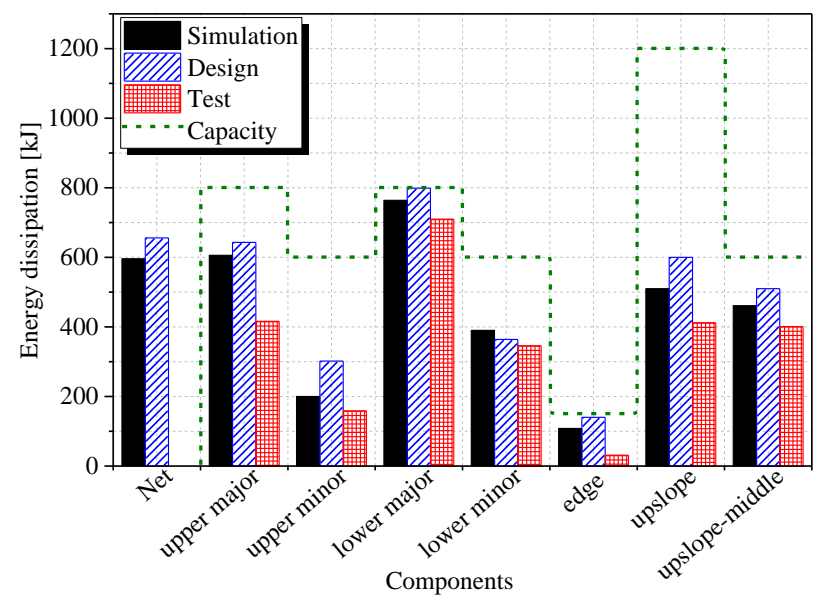

Fig. 32. Comparison of the dissipated energy distribution among the components of barrier 3500 .
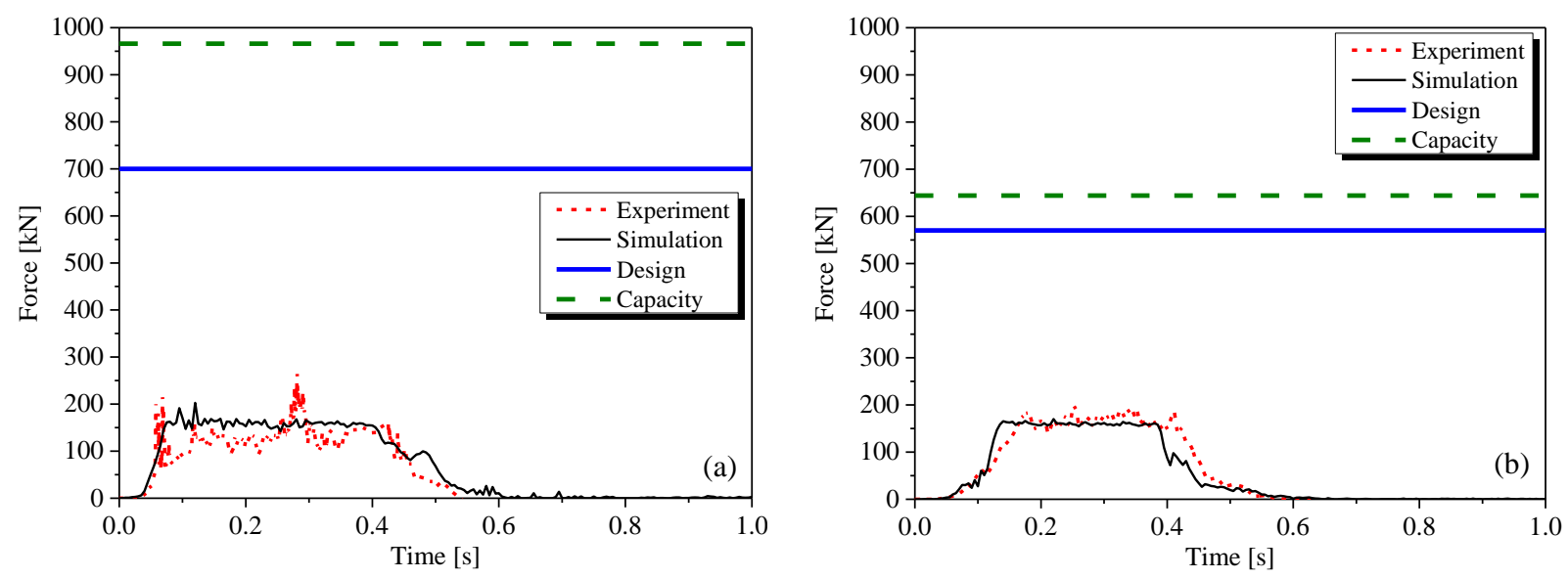

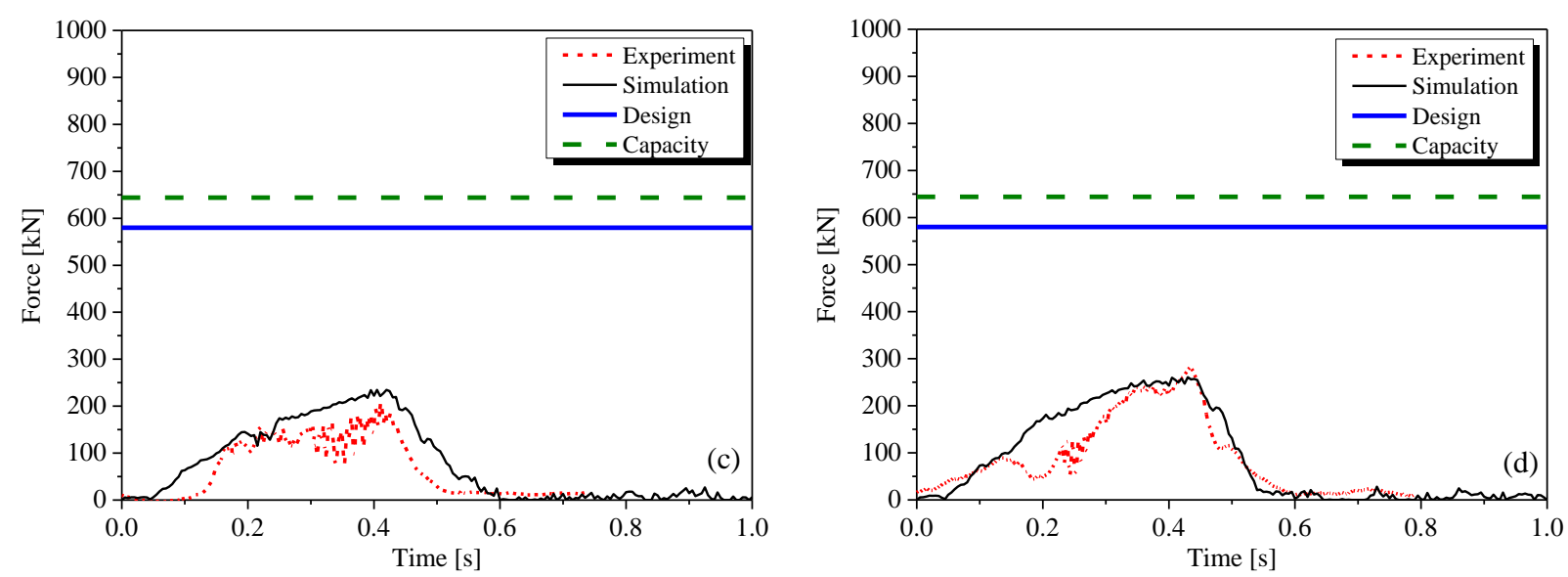

Fig. 33. Comparison of internal forces in the ropes obtained experimentally and numerically: (a) upper major support rope (left lateral side); (b) lower minor support rope (left lateral side); (c) and (d) upslope ropes (connected with the middle module).

In Fig. 33, the internal forces of the ropes recorded by the load cells (red curves) in the field test, as well as the design values derived from Eq. (7), the actual breaking forces (in the figure indicated as 'capacity') and the simulation results (black curves) of selected wire ropes are shown. The excellent agreement between the simulation (black curves) and the test (red curves) proves the accuracy of the numerical approach once again. By comparing the peak forces of test and design data, it can be seen that all design values (blue lines) are more than two times higher, supplying an enough safety margin, that is important for structures subjected to impact loads.

\section{CONCLUSIONS}

In the present paper, an efficient and reliable design procedure to devise the main components (wire-ring net, energy dissipating devices and ropes) of flexible rockfall protection barriers was presented. The design approach was based on a robust finite element numerical model. To obtain the key parameters for the numerical model, several experimental tests were conducted on the main barrier components, involving the wire-ring net and the energy dissipating devices. In particular, to define the force-displacement curve, the ring brakes were subjected to quasi-static tests following the ETAG027 recommendations. However, it is well known that dynamic tests would have allowed to characterize the behavior of the energy dissipating devices as they work in situ. Nevertheless, results showed that the developed model was able to represent the mechanical behavior of the components and to predict to a satisfying level the dissipated energy during the tests. Once the model was optimally tuned, a further assessment was conducted considering full-scale tests on a barrier prototype of nominal energy level of $1500 \mathrm{~kJ}$, which included both SEL and MEL impacts. The good agreement of internal forces and deformability of the structure, ensured the accuracy of the numerical model to be employed as a design tool. It should be noted that the validation of rope forces between test and simulation was done considering measured forces that were transferred to the anchorages by the energy dissipating elements. The energy dissipating element acts as a filter during the braking time, limiting the force when the element is activated. Once the maximum elongation of the brake is reached, the system composed by the brake and the cable behaves like a single cable. The test results from the load cells mounted at the end of the ropes in the barrier showed that the measured forces were bigger than the brake activation force, indicating that the peak 
forces were not influenced by the presence of the brakes.

Based on the model, the energy distribution during the block impact among the different barrier components was analyzed in detail. According to the ratio between the total energy and the nominal energy, the design energy was defined, which was supposed to be consumed completely in terms of the internal energy of the barrier structure. Other models of barrier prototypes of several nominal energies ranging from 750 to $5000 \mathrm{~kJ}$ were developed in order to investigate the trend of the absorbed energy in the wire-ring nets and in the energy dissipating devices. Besides, the design values for internal forces of wire ropes were determined by considering adequate safety ratios, according to the peak forces extracted from the simulations.

At last, another full-scale test of a barrier structure with an unconventional nominal energy level of $3500 \mathrm{~kJ}$ was carried out to assess the design procedure. Test results proved that the new design method had accurately predicted and allocated energy dissipation of each component, while, the design value for rope internal forces was determined with enough reservation margin.

It should be clarified that the parametric values employed in the proposed methodology, such as the energy allocating ratios among the different components, are determined for the present type of barrier systems. Nevertheless, for other types of flexible barriers with different components or connection measures, the design procedure based on energy allocation can be adopted recalibrating the key parameters by following the presented approach.

\section{Acknowledgements}

This study is supported by the National Natural Science Foundation of China (Grant No. 51678504, 51408498), Department of Science and Technology of Sichuan Province (Grant No. 2018JY0029), Open Fund of National Engineering Laboratory for Bridge Structure Safety Technology (Grant No. 310821151102), the Fund of State Key Laboratory of Geohazard Prevention and Geoenvironment Protection (Grant No. SKLGP2016K013), and China Scholarship Council (Grant No. 201607005124).

Besides, OST Slope Protection Engineering Co. (Sichuan, China) is also acknowledged for allowing using the data presented in the paper.

The LAMC (Laboratory of Computational Mechanics) lab facilities of the DICAM Department, University of Bologna (Italy), are gratefully acknowledged.

\section{References}

[1] Lambert S, Nicot F. Rockfall Engineering. ISTE Ltd and John Wiley \& Sons Inc; 2011. ISBN: 978-184821-256-5.

[2] Hoek E. Practical Rock Engineering. RocScience; 2007.

[3] Peila D, Oggeri C, Castiglia C. Ground reinforced embankments for rockfall protection: Design and evaluation of full scale tests. Landslides 2007;4:255-65.

[4] Escallón J, Wendeler C. Numerical simulations of quasi-static and rockfall impact tests of ultra-high strength steel wire-ring nets using Abaqus/Explicit. In: 2013 SIMULIA Community Conference 1;2013. 
[5] Volkwein A, Gerber W. Stronger and lighter-evolution of flexible rockfall protection systems. In: IABSEIASS 2011 London Symposium Report: Taller, Longer, Lighter. Meeting growing demand with limited resources; the 35th Annual Symposium of IABSE, the 52nd Annual Symposium of IASS and incorporating the 6th International Conference on Space Structures; 2011.

[6] Zhao SC, Yu ZX, Zhao L, Qi X, Wei T. Damage mechanism of rockfall barriers under strong impact loading. Engineering Mechanics 2016;33(10):24-34. http://dx.doi.org/10.6052/j.issn.1000-4750.2016.06.ST08 (in Chinese).

[7] Peila D, Pelizza S, Sassudelli F. Evaluation of behaviour of rockfall restraining nets by full scale tests. Rock Mech Rock Eng 1998; 31:1-24.

[8] Gerber W. Field testing of rockfall protection barriers a comparison between inclined ropeway and vertical crane testing. Tech. rep., Swiss Agency for the Environment, Forests and Landscape (SAEFL) and the Swiss Federal Research Institute WSL; 2001.

[9] Gottardi G, Govoni L. Full-scale modelling of falling rock protection barriers. Rock Mech Rock Eng 2010; 43:261-274.

[10] Smith DD, Duffy JD. Field tests and evaluation of rockfall restraining nets. Tech. rep., California Dept. of Transportation; 1990.

[11] Buzzi O, Spadari M, Giacomini A, Fityus S, Sloan SW. Experimental testing of rockfall barriers designed for the low range of impact energy. Rock Mech Rock Eng 2013; 46(4):701-712.

[12] Bigot C, Berger F, Lambert S. Treenet. An innovative type of rockfall protection fence on forested slopes specially designed for low energy events. In: International Symposium in Pacific Rim; 2010.

[13] Duffy JD, Haller B. Field tests of flexible rockfall barriers. In: Proceeding of the Conference on Transportation Facilities through Difficult Terrain; Aspen, Colorado (USA) 1993:465-73.

[14] Peila D, Ronco C. Technical Note: Design of rockfall net fences and the new ETAG 027 European guideline. Nat Hazards Earth Syst Sci 2009;9:1291-8.

[15] EOTA. Guideline for European technical approval of falling rock protection kits (ETAG 027), 2012, Brussels.

[16] NRAPRC. Rockfall impact test method and evaluation of railway slope flexible passive protection product, 2016, China (in Chinese).

[17] AASHTO. Recommended procedures for the testing of rock-fall barriers, 2003, US.

[18] Peng H, Ling X. Optimal design approach for the plate-fin heat exchangers using neural networks cooperated with genetic algorithms. Appl Therm Eng 2008;28:642-50.

[19] Liu Z, Li H, Liu K, Yu H, Cheng K. Design of high-performance water-in-glass evacuated tube solar water heaters by a high-throughput screening based on machine learning: A combined modeling and experimental study. Sol Energy 2017;142:61-7.

[20] Gentilini C, Govoni L, de Miranda S, Gottardi G, Ubertini F. Three-dimensional numerical modelling of falling rock protection barriers. Comput Geotech 2012; 44:58-72.

[21] Cazzani A, Mongiovì L, Frenez T. Dynamic finite element analysis of interceptive devices for falling 
rocks. Int J Rock Mech Min 2002; 39:303-321.

[22] Govoni L, de Miranda S, Gentilini C, Gottardi G, Ubertini F. Modelling of falling rock protection barriers. Int J Phys Model Geo 2011; 11:126-137.

[23] de Miranda S, Gentilini C, Gottardi G, Govoni L, Ubertini F. A simple model to simulate the full-scale behaviour of falling rock protection barriers. In: Physical Modelling in Geotechnics - Proceedings of the 7th International Conference on Physical Modelling in Geotechnics; 2010:1247-52.

[24] de Miranda S, Gentilini C, Gottardi G, Govoni L, Mentani A, Ubertini F. Virtual testing of existing semirigid rockfall protection barriers. Eng Struct 2015; 85:83-94.

[25] Volkwein A. Numerical simulation of flexible rockfall protection systems. In: ASCE, editor. Proceedings of the International Conference on Computing in Civil Engineering; 2005.

[26] Hearn G, Barret RK, Henson HH. Development of effective rockfall barriers. J Transp Eng 1995; 121(6): $507-516$.

[27] Escallón, JP, Boetticher v A, Wendeler C, Chatzi E, Bartelt P. Mechanics of chain-link wire nets with loose connections. Eng Struct 2015;101:68-87.

[28] Nicot F, Cambou B, Mazzoleni G. Design of rockfall restraining nets from a discrete element modelling. Rock Mech Rock Engng 2001; 34(2):99-118.

[29] Bertrand D, Trad A, Limam A, Silvani C. Full-scale dynamic analysis of an innovative rockfall fence under impact using the discrete element method: from the local scale to the structure scale. Rock Mech Rock Eng 2012;45:885-900.

[30] Bourrier F, Lambert S, Baroth J. A reliability-based approach for the design of rockfall protection fences. Rock Mech Rock Eng 2015;48:247-259.

[31] de la Cruz Alcala G. Design and modelling by discrete elements of tree-anchored rockfall protection fences. Master's thesis, University of Castilla-La Mancha (Spain) 2016.

[32] Gentilini C, Gottardi G, Govoni L, Mentani A, Ubertini F. Design of falling rock protection barriers using numerical models. Eng Struct 2013;50: 96-106.

[33] Volkwein A, Roth A, Gerber W, Vogel A. Flexible rockfall barriers subjected to extreme loads. Struct Eng Int 2009;19:327-32.

[34] Nicot F, Cambou B, Mazzoleni G. From a constitutive modelling of metallic rings to the design of rockfall restraining nets. Int J Numer Anal Meth Geomech 2001; 25: 49-70.

[35] Spadari M, Giacomini A, Buzzi O, Hambleton JP. Prediction of the bullet effect for rockfall barriers: a scaling approach. Rock Mech Rock Eng 2012;45:131-44.

[36] Kwan JSH, Chan SL, Cheuk JCY, Koo RCH. A case study on an open hillside landslide impacting on a flexible rockfall barrier at Jordan Valley, Hong Kong. Landslides 2014;11:1037-50.

[37] Luciani A, Todaro C, Peila D. Maintenance and risk management of rockfall protection net fences through numerical study of damage influence. Frattura ed Integrità Strutturale 2018;12:241-50.

[38] Dimasi C, Luciani A, Martinelli D, Paganone M, Peila D. Control of rockfall protection net fences for management and maintenance. Geoingegneria Ambientale e Mineraria 2015;146:65-71. 
[39] De Biagi V, Lia Napoli M, Barbero M, Peila D. Estimation of the return period of rockfall blocks according to their size. Nat Hazards Earth Syst Sci 2017;17:103-13.

[40] Corominas J, Van Westen C, Frattini P, Cascini L, Malet J-P, Fotopoulou S, Catani F, Van Den Eeckhaut M, Mavrouli O, Agliardi F, Pitilakis K, Winter MG, Pastor M, Ferlisi S, Tofani V, Hervás J, Smith JT. Recommendations for the quantitative analysis of landslide risk. B Eng Geol Environ 2014;73:209-263.

[41] Moon T, Oh J, Mun B. Practical design of rockfall catchfence at urban area from a numerical analysis approach. Eng Geo 2014, 172:41-56.

[42] Giani GP, Giacomini A, Migliazza M, Segalini A. Experimental and theoretical studies to improve rock fall analysis and protection work design. Rock Mech Rock Engng 2004;37(5):369-89.

[43] Pierson LA, Gullixson CF, Chassie RG. Rockfall catchment area design guide. Tech. rep., Oregon Department of Transportation \& Federal Highway Administration; 2001.

[44] Muhunthan B, Hattamleh OA, Badger TC, Lowell SM, Duffy JD. Analysis and design of wire mesh / cable net slope protection. Tech. rep., Washington State Transportation Center; 2005.

[45] Steel wire ring net panels - Definitions and specifications. International Organization for Standardization, ISO 17745:2016.

[46] Bertolo P, Oggeri C, Peila D. Full-scale testing of draped nets for rock fall protection. Can Geotech J 2009;46:306-17.

[47] Bonati A, Galimberti V. La valutazione sperimentale di sistemi di difesa attiva dalla caduta massi. In Proceedings of the Conference Bonifica dei versanti rocciosi per la protezione del territorio. Trento (Italy) 2004:177-189 (In Italian).

[48] Wang M, Shi S, Yang Y. Static tensile test and FEM dynamic simulation for a ring-brake energy dissipator. J Vib Shock 2011;30(4):188-193. http://dx.doi.org/10.13465/j.cnki.jvs.2011.04.035 (in Chinese).

[49] LS-Dyna Theory Manual, Livermore Software Technology, California; 2006.

[50] Dhakal S, Bhandary NP, Yatabe R, Kinoshita N. Numerical and analytical investigation towards performance enhancement of a newly developed rockfall protective cable-net structure. Nat Hazards Earth Syst Sci 2012;12:1135-49.

[51] Escallón JP, Wendeler C, Chatzi E, Bartelt P. Parameter identification of rockfall protection barrier components through an inverse formulation. Eng Struct 2014;77:1-16.

[52] Torkar M, Arzenšek B. Failure of crane wire rope. Eng Fail Anal 2002;9:227-233.

[53] Cargnel G. Tests on steel wire and cable net meshes. Geoengineering Environment and Mining 201;GEAM 132:65-74.

[54] Zhao SC, Yu ZX, Wei T, Qi X. Test study of force mechanism and numerical calculation of safety netting system. China Civ Eng J 2013;46(5):122-128. http://dx.doi.org/10.15951/j.tmgcxb.2013.05.009 (in Chinese).

[55] Grassl H, Volkwein A, Bartelt P, Wartmann S. Experimental and numerical modelling of highly flexible rockfall protection barriers. In Proceedings of 12th Panamerican Conference on Soil Mechanics and Geotechnical Engineering, Cambridge, Massachusetts (USA) 2003:2589-94.

[56] Castanon-Jano L, Blanco-Fernandez E, Castro-Fresno D, Ballester-Munoz F. Energy dissipating devices 
in falling rock protection barriers. Rock Mech Rock Eng 2017; 50(3): 603-619.

[57] Tracker Manual, Open Source Physics, 2017.

[58] JGJ 276. Technical code for safety of lifting in construction. 2012, MOHURD, China.

[59] Yu ZX, Qiao YK, Zhao L, Xu H, Zhao SC, Liu YP. A simple analytical method for evaluation of flexible rockfall barrier Part 1: Working mechanism and analytical solution. Adv Steel Constr 2018; 14: 115-141.

[60] Yu ZX, Qiao YK, Zhao L, Xu H, Zhao SC, Liu YP. A simple analytical method for evaluation of flexible rockfall barrier Part 2: Application and full-scale test. Adv Steel Constr 2018;14:142-165.

[61] GB/T 20118. Steel wire ropes for general purpose (ISO/DIS 2408:2002 Steel wire ropes general purposesMinimum requirements, MOD). 2006, AQSIQ, China. 